University of Redlands

\title{
3D Indoor Routing and Visualization for the University of Redlands
}

\author{
A Major Individual Project submitted in partial satisfaction of the requirements \\ for the degree of Master of Science in Geographic Information Systems \\ by \\ Umar Makdoom \\ Mark Kumler, Ph.D., Committee Chair \\ Nader Afzalan, Ph.D.
}

December 2015 
3D Indoor Routing for University of Redlands

Copyright (C) 2015

by

Umar Makdoom 
The report of Umar Makdoom is approved.

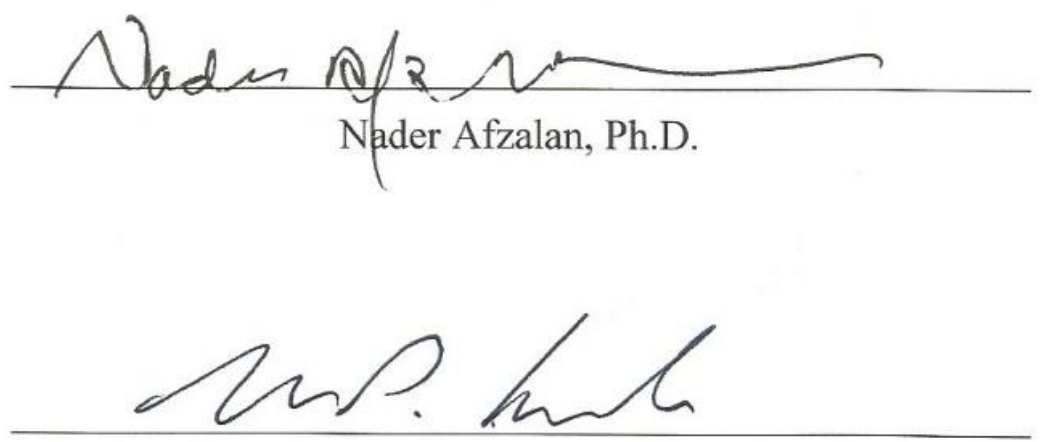

Mark Kumler, Ph.D., Committee Chair

December 2015 



\section{Acknowledgements}

First and foremost, I thank Allah for everything He has given me in this life. I hadn't thought that I'm going to continue my masters degree abroad, but since the King Abdullah scholarship started, my dream came true. I express my sincere gratitude for the scholarship, which allowed me to study in the United States of America. I appreciate my parents who always look after me and lead me to the right decisions in my life. Thanks to my awesome siblings who are in my life every single day, even though I live in a different time zone.

I also thank Allah for giving me such an amazing friend, Fisal Basheeh, who is always next to me since middle school until he officially became my brother in-law. I couldn't live in a foreign country without his support. I also thank both Antje Kunze and Jan Halatsch who gave me the opportunity to work with them. They invested their time in teaching me skills in CityEngine and CloudCities software. They were fully patient with me since I did not have any expertise with the software.

Special thanks to my advisor Dr. Mark Kumler for his advice, support and encouragements. Great thanks to all my friends in Cohorts 24, 25, 25.5 and 26 who were great friends to share with me GIS skills and fun time. Joseph, you were my closest international friend of mine, thanks for your time being next to me when I needed you. It is impossible to mention all the people who influenced me in a positive way during my two-year program, you made me feel happy in this program. 



\author{
Abstract \\ 3D Indoor Routing for University of Redlands \\ by \\ Umar Makdoom
}

The University of Redlands contains quite a number of buildings with complex details. The university website does not have an interactive map that users such as students can use for orientation around the campus. Even though the data exist and they are able to use them to develop spatial tools, 3D tools have not been developed yet. The goal of this project is to develop a proof of concept for 3D indoor routing using the University of Redlands as a study case. The project is implemented to accommodate two scenarios for the routing analysis: Handicapped and Elevator, and Non-handicapped and Stairs. These results will be accessible for users through a web browser as 3D web scene for visualization purpose.

The ArcGIS Network Analyst extension was used to build the route scenarios. The tool was developed to run only within the ArcGIS for Desktop environment. To run the tool, a user needs to open the scene and the tool interface from the ArcScene application, then enter the parameter of the desired scenario and run the tool. This would create a 3D route among the desired points of interest. The 3D model was developed in CityEngine and published as a web scene hosted in CloudCities with sample results of the two scenarios. Users are able to view the 3D scene and route results through a web browser. The web scene dashboard was customized to visualize the interactive 3D scene. 



\section{Table of Contents}

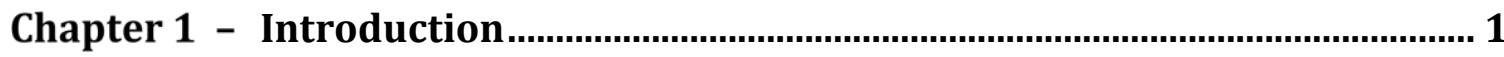

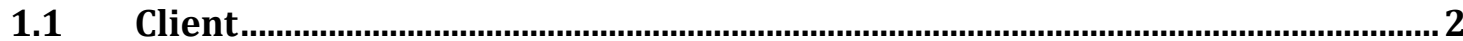

1.2 Problem Statement........................................................................................ 2

$1.3 \quad$ Proposed Solution.................................................................................... 2

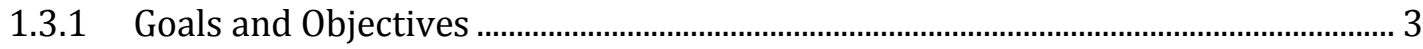

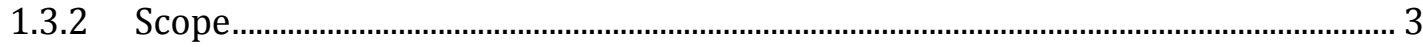

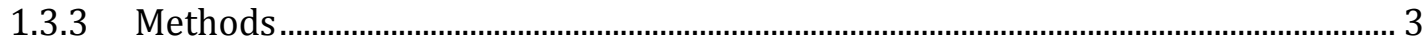

1.4 Audience ...................................................................................................... 4

$1.5 \quad$ Overview of the Rest of this Report ................................................................... 4

Chapter 2 - Background and Literature Review …….......................................... 5

2.1 3D Modeling ………........................................................................................ 5

2.2 ArcGIS Network Analyst Extension ........................................................................ 6

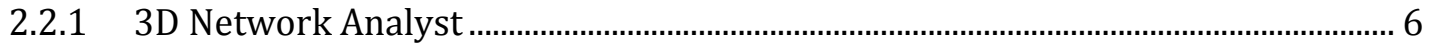

2.2.2 The 3D Indoor Routing..................................................................................................

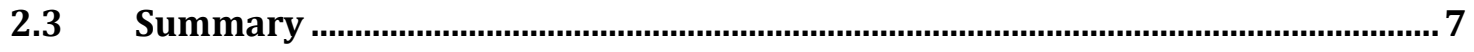

Chapter 3 - Systems Analysis and Design .............................................................. 9

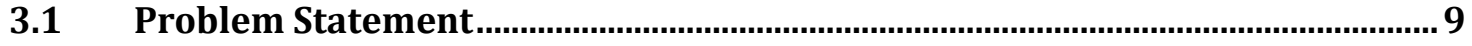

3.2 Requirements Analysis ...........................................................................

3.3 System Design.................................................................................................. 12

3.4 Project Plan ........................................................................................................... 13

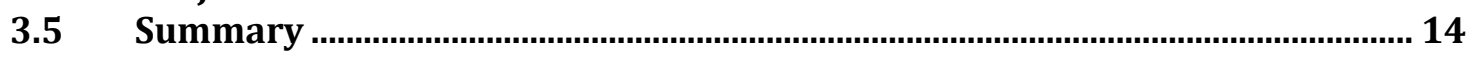

Chapter 4 - Database Design ....................................................................15

4.1 Conceptual Data Model ................................................................................ 15

4.2 Logical Data Model.......................................................................................... 17

4.3 Data Sources..................................................................................................... 19

4.4 Data Collection Methods .................................................................................. 19

4.5 Data Scrubbing and Loading …………….......................................................... 19

4.6 Summary ........................................................................................................ 19

Chapter 5 - Implementation ................................................................................21

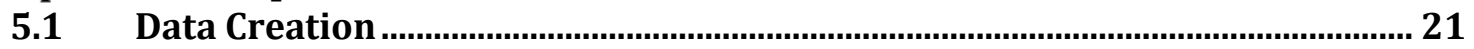

5.1.1 CAD Data Conversion.....................................................................................................22

5.1.2 Feature Class Enhancement.............................................................................................23

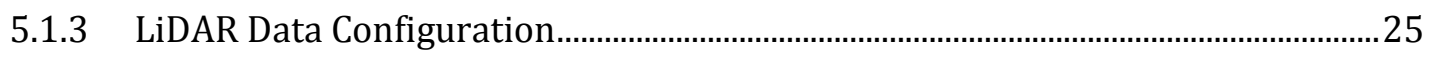

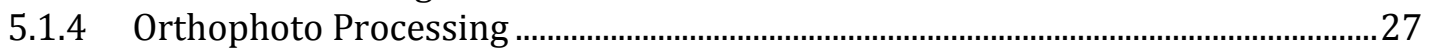

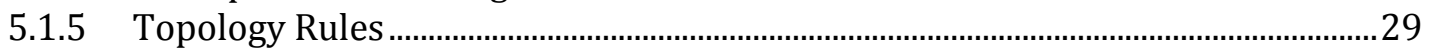

5.2 3D Indoor Routing Analysis............................................................................ 29

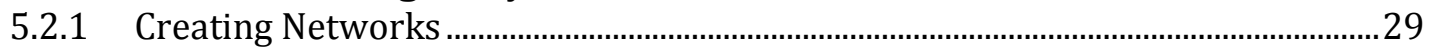

5.2.2 Building the Network Dataset......................................................................................32

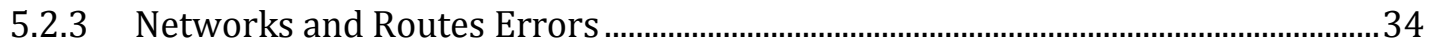

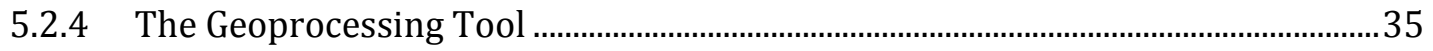

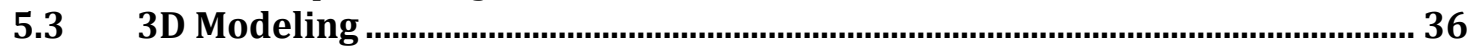

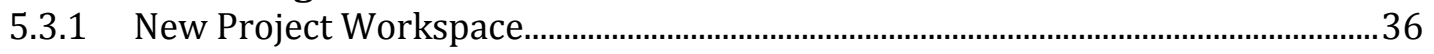

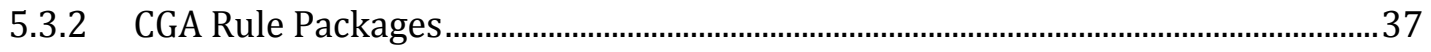

5.3.3 CityEngine Challenges ...................................................................................................... 


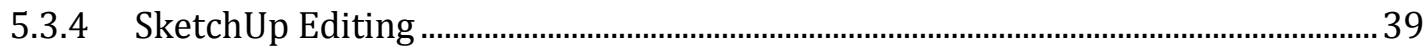

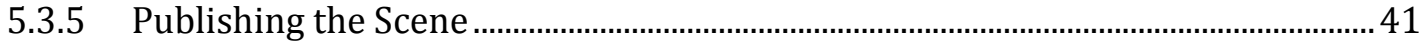

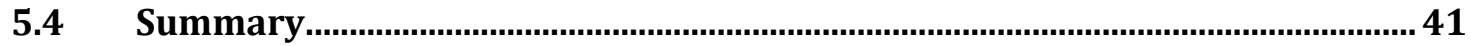

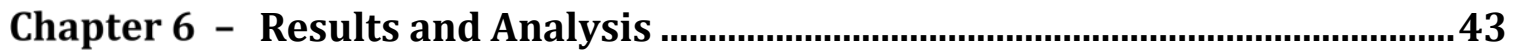

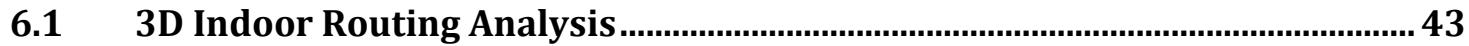

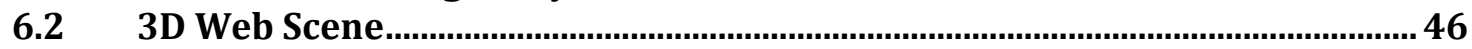

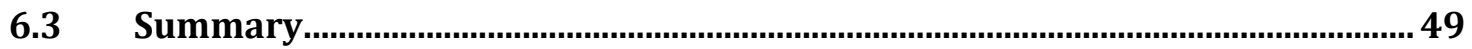

Chapter 7 - Conclusions and Future Work …..........................................................51

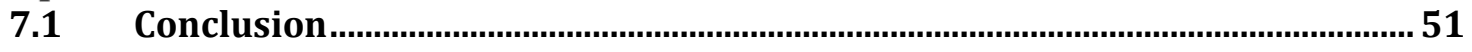

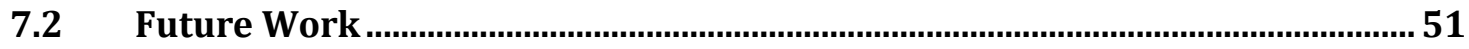

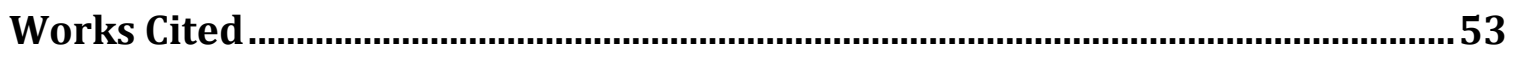

Appendix A. 3D Indoor Routing Web Scenes ..................................................... 55

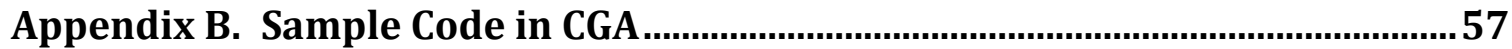




\section{Table of Figures}

Figure 1-1: University of Redlands in City of Redlands, CA...Error! Bookmark not defined.

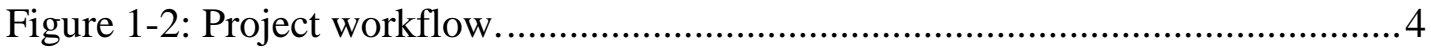

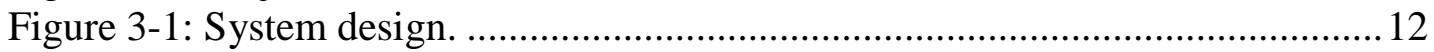

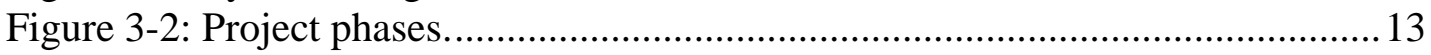

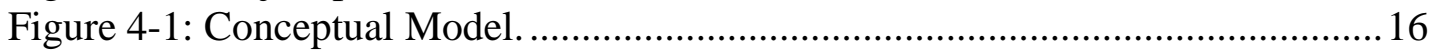

Figure 4-2: Logical Model.............................................................................. 18

Figure 5-1: Converted CAD data floor plan of Appleton Hall into a Feature class. . 22

Figure 5-2: Missing features in Basemap feature class. ..........................................23

Figure 5-3: Appleton Hall First Floor Boundary....................................................24

Figure 5-4: LiDAR data for Appleton Hall..........................................................26

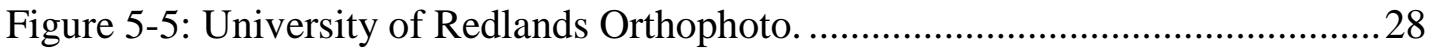

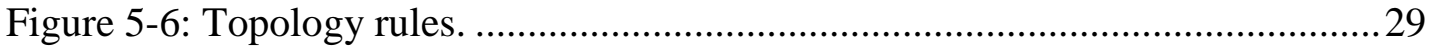

Figure 5-7: 2D views for Indoor and Outdoor network feature classes..................... 31

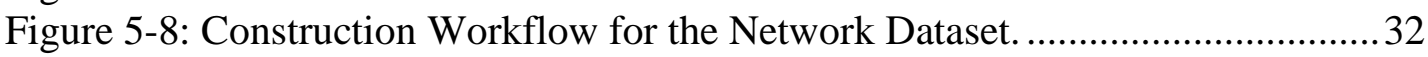

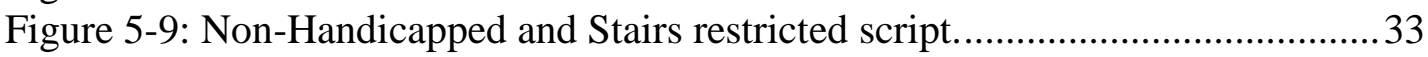

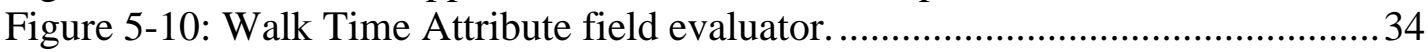

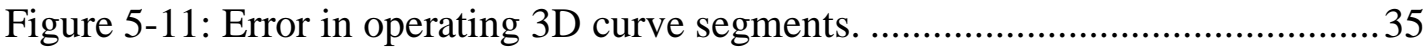

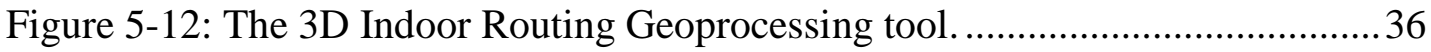

Figure 5-13: The Campus rule package defining window and door elements. .......... 37

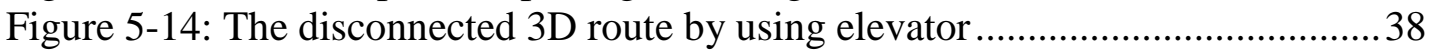

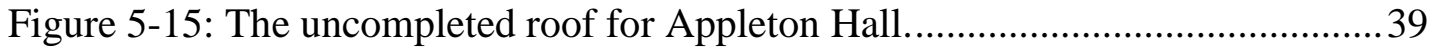

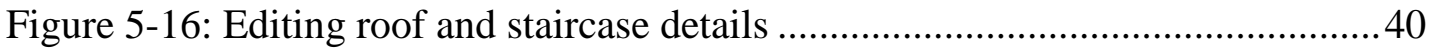

Figure 5-17: The 3D web scene hosted in CloudCities. ....................................... 41

Figure 6-1: The 3D Indoor routing Geoprocessing tool Interface. .......................... 44

Figure 6-2: The Non-Handicapped and Stairs restricted uses scenario. ....................45

Figure 6-3: Route between indoor and outdoor networks using stairs scenario.........46

Figure 6-4: The 3D web scene for the University of Redlands. ..............................47

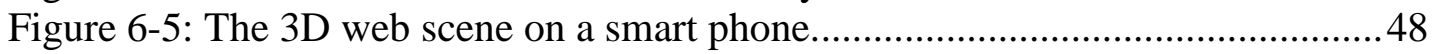

Web scene 1: 3D sample route of Handicap and Elevator use. ...............................55

Web scene 2: 3D sample route of Non-Handicapped and stairs use. .......................56

Web scene 3: 3D campus for University of Redlands-Mobile ...............................56 



\section{List of Tables}

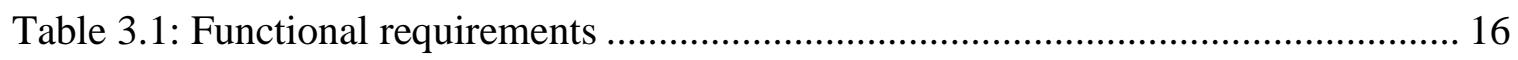

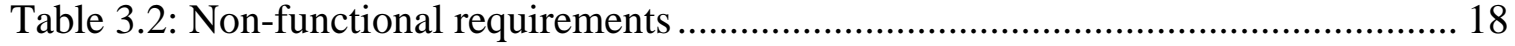





\section{List of Acronyms and Definitions}

$\begin{array}{ll}\text { CAD } & \text { Computer-Aided Design } \\ \text { CGA } & \text { Computer Generated Architecture } \\ \text { DTM } & \text { Digital Terrain Model } \\ \text { GIS } & \text { Geographic Information Systems } \\ \text { GP } & \text { Geoprocessing } \\ \text { GUI } & \text { Graphical User Interface } \\ \text { HTML } & \text { Hyper Text Markup Language } \\ \text { KMZ } & \text { Keyhole Markup language Zipped } \\ \text { LAS } & \text { LIDAR Data Exchange File } \\ \text { LiDAR } & \text { Light Detection and Ranging } \\ \text { POI } & \text { Point Of Interest } \\ \text { SXD } & \text { 3D Scene Document } \\ \text { TIN } & \text { Triangulated Irregular Network } \\ \text { U of R } & \text { University of Redlands } \\ \text { USGS } & \text { United States Geological Survey } \\ \text { WebGL } & \text { Web Graphics Library } \\ \text { 2D } & \text { Two Dimensions } \\ \text { 3D } & \text { Three Dimensions } \\ \text { 3WS } & \text { 3D Web Scene }\end{array}$





\section{Chapter 1 - Introduction}

In the recent past, there has been an increasing number of projects focusing on indoor routing technologies to provide users with navigation tools to be used inside buildings. These projects have been implemented using 3D routing technologies mainly in airports, shopping malls, and hotels. Most of the currently implemented navigation and routing focused projects have been developed for outdoor areas, not indoor. Though 3D technology has grown widely in recent years, driven by the demand for more realistic visualizations, this technology has been widely applied in outdoor environments. In addition, most of the projects carried out for indoor routing have implemented two dimensional technology for representing objects. Among the very few indoor routing projects done using 3D technology was one carried out by Goetz (2012). According to Goetz, most of the existing 3D indoor routing services utilize proprietary software or plug-ins, a factor that highly affected the accessibility and spread of the results to the public. Goetz found that most of the indoor solutions are limited as not very many people can use them on their mobile phones or personal computers. SmarterBetterCities, a forprofit company, wanted to develop a 3D indoor routing for the University of Redlands, California (Figure 1-1) as a proof of concept for their business.

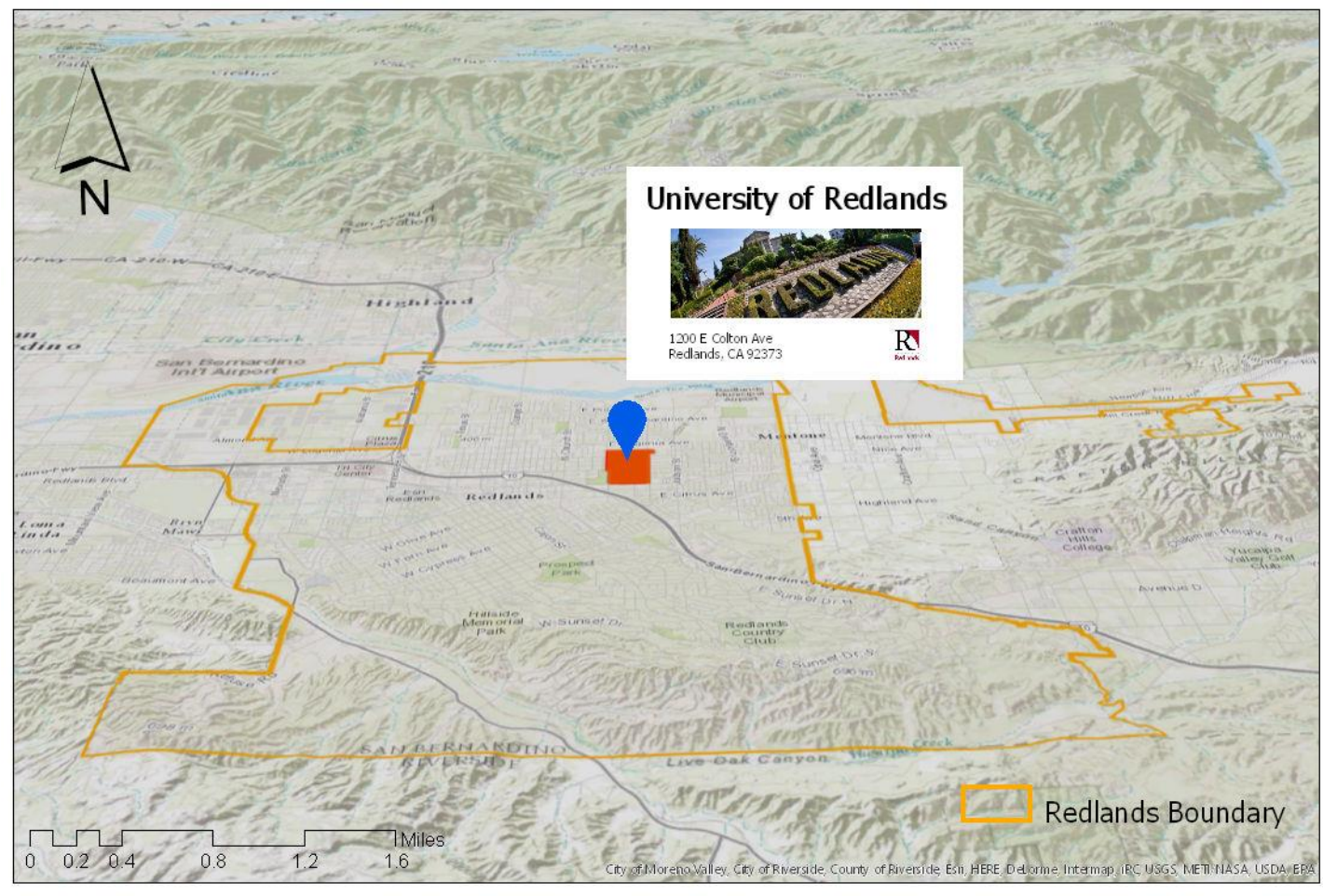

Figure 1-1: University of Redlands in City of Redlands, CA. 


\subsection{Client}

The client for this project was Ms. Antje Kunze of SmarterBetterCities, a company headquartered in Zurich, Switzerland. SmarterBetterCities is specialized in visualization of 3D models to support decision making solutions by sharing stories via web tools. The privately owned company develops 3D geospatial solutions for decision makers such as local governments, municipalities, and construction companies. Ms. Kunze is a cofounder and the Chief Executive Officer of the company. Her career background is in architecture and information visualization. Her responsibilities in this project were to provide data and technical advice, as well as being the point of contact for the project planning, quality assurance and acceptance of the developed solution.

\subsection{Problem Statement}

The University of Redlands lacked three-dimensional (3D) routing tools for its campus and facilities. Most of the campus buildings and facilities have complex architectural designs and are comprised of many rooms and accessories (fire exits, fire extinguishers, etc.) that users find difficult to locate. Moreover, the campus hosts frequent meetings and gatherings, which are comprised of visitors with special needs (handicapped). The meeting attendees and visitors are not familiar with the buildings and facilities on the campus. This makes it very difficult for them to move within buildings and across campus without wasting time. It is this problem of accessing various facilities and amenities within campus that triggered the need for this project. The project addressed two parts of the large general problem: determining optimal exit routes from one specific building, Appleton Hall, and visualizing routes within Appleton Hall in three dimensions.

\subsection{Proposed Solution}

The proposed solution used 3D GIS technology to provide visualization and use a 3D routing geoprocessing tool to navigate within the campus buildings and facilities. The solution for the first part of the problem entailed using the 3D Network Analyst geoprocessing (GP) tool, one of many tools within the Network Analyst extension to ArcGIS for Desktop. This tool identified the optimal route out of a building based on user input and parameters. The solution to the second part of the problem involved building a scene within CityEngine and publishing it as a web scene hosted by CloudCities. This web scene allowed for the visualization of different route scenarios.

Since the project was a proof of concept, s single University of Redlands building was chosen as the project area. The tool was built as a 3D routing GP tool that ran within the ArcScene application of ArcGIS for Desktop, while the web scene was made to be accessed from a web browser. By using 3D GIS technology on the browser, the web scene enabled both visualization and representation of the 3D design model of the project area. Applying the GIS in this project helped realize the project goal, as the technology has visualization and analytical capabilities that were foreseen to validate the proof of concept for the project.

As part of the solution, CityEngine was used as it supports an abundance of urban planning decision-making tasks like the generation of 2D floor plans, texture, and even conversion of $2 \mathrm{D}$ to $3 \mathrm{D}$ models. Moreover, rendering the $3 \mathrm{D}$ models was done using the 
Computer Generated Architecture (CGA) programming language in CityEngine. The ArcScene application, within ArcGIS Desktop 10.3 was used to run the 3D routing GP tool, in order to identify the best routes between points of interest within the project area. The final product of this project was an indoor routing GP tool and web scene. The 3D web scene illustrated sample the best routes an interactive 3D between two or more interesting points within Appleton Hall.

\subsubsection{Goals and Objectives}

The overall goal of this project was to validate the feasibility of implementing a 3D indoor routing model and 3D model within a campus. Appleton Hall, a building on the campus of the University of Redlands, was used as the project area for the proof of concept. The overall goal was realized through the implementation of the following specific products:

1. A geodatabase for the University of Redlands ( $U$ of $R$ ) campus buildings and facilities.

2. 3D objects for University of Redlands ( $U$ of $R$ ) in the CityEngine environment.

3. A 3D routing GP tool using Model Builder that allows users to identify the best routes between points of interest within the facilities.

4. A web scene with a sample of indoor routing results.

\subsubsection{Scope}

This project focused on one building, Appleton Hall, at the University of Redlands in Redlands, California. The prototype project targeted a variety of users, including an audience with no existing GIS skills, thus a web scene was published to enable these users to access the sample results of the routing tool. The users would be able to visit and view the 3D models as well as the samples of selected 3D routing results. In addition, the web scene provided other functions such as: search for a specific building, zoom in and out, capture screenshots, view pop-up windows for more information, and interact with a basemap. Furthermore, the project included a 3D indoor routing GP tool that could run in the ArcScene environment to create the best route between two or more points selected by a user.

Most of the project data were provided by the Center for Spatial Studies at the University of Redlands. The project utilized feature classes, CAD data, Lidar data, and an orthophoto of the campus area. The project data were stored in a file geodatabase.

\subsubsection{Methods}

This project utilized Esri products including ArcGIS Desktop version 10.3, Model Builder, and CityEngine version 2014.1 to implement the 3D indoor routing. Figure 1-2 illustrates the project workflow. The ArcCatalog application was used to design the file geodatabase, create the network dataset, and apply some topology rules. The ArcMap application was used to clean up and digitize the geometry, specify the spatial reference of the data, edit field-collected data, and read the LiDAR data. Model Builder was used to alter the geoprocessing tool to suit the project and build the relationship between network elements. The ArcScene application was used to visualize 3D objects, run the 3D indoor 
routing GP tool, and export multipath geometry. The 3D model was extruded, designed, and textured by using the Computer Generated Architecture (CGA) programming language within CityEngine. The final web scene was published from CityEngine to CloudCities so that it could be accessed from a web browser. The CloudCities dashboard was customized to include more functions such as search, zoom in and out, and capture screenshots as necessary for the project.

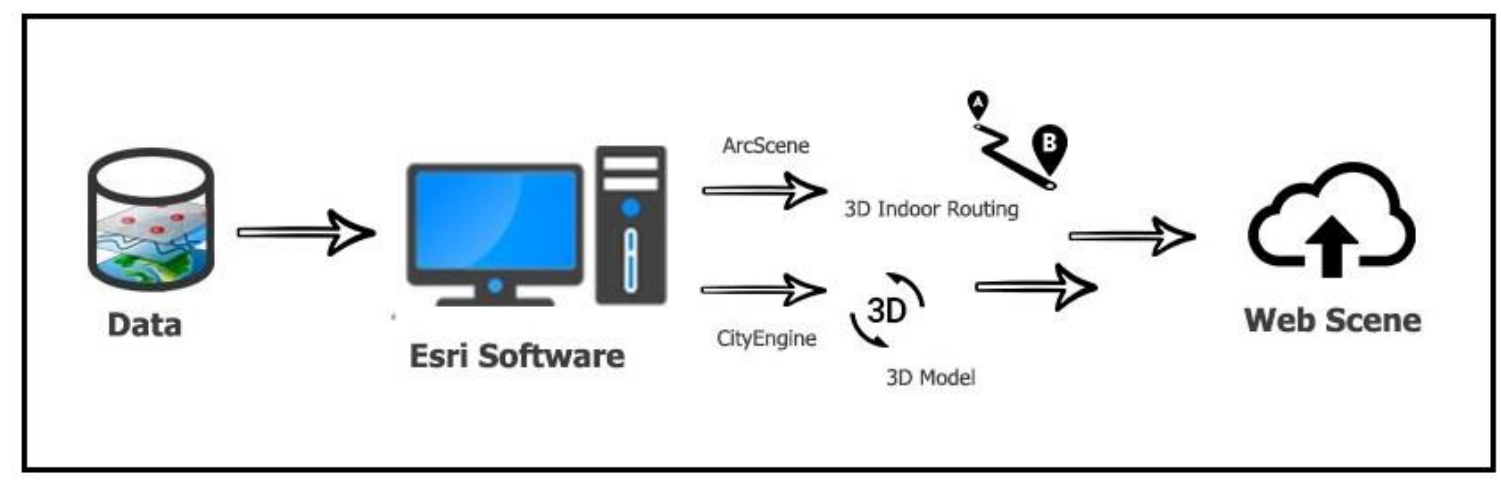

Figure 1-2: Project workflow.

\subsection{Audience}

This project targeted a wide range of novice and expert users including:

1. Campus visitors.

2. University administrators.

3. Faculty.

4. Staff.

5. Students.

6. GIS professionals at the Center for Spatial Studies.

\subsection{Overview of the Rest of this Report}

The rest of this report is organized into six chapters. These chapters provide more details and information about: related projects, implementation method and workflows, and overview of suggested recommendations for future projects. Chapter 2 discusses previous projects and research that used 3D indoor routing. It highlights technologies which have been applied in these previous projects and also examines their strengths and shortcomings. Chapter 3 covers all the system design, project requirements, and project plan. Chapter 4 is a discussion of the database design including the conceptual model and logical data model, while chapter 5 expounds on the implementation process. Chapter 6 presents the results of the analysis. Chapter 7 includes a summary of the project, conclusion, and possible future works. 


\section{Chapter 2 - Background and Literature Review}

This chapter is a discussion of previous projects done within the domain of indoor routing. The chapter looks into the various related projects that offer solutions for 3D indoor routing, and the importance of 3D technologies. In addition, the limitations of technologies and solutions used by researchers in these previous studies are discussed. The chapter is organized into three sections: 3D Modelling, Indoor Routing, and Summary.

\subsection{D Modeling}

With the growing popularity of 3D GIS technologies, the creation of models to represent geography has grown and is used in many projects. The studies considered in this chapter utilized 3D software such as SketchUp and CityEngine to create models that mimic the real world. The growth of 3D technologies has led to development of 3D real world representation of features, as well as the ability to perform spatial analysis using 3D representations. The 3D technologies have also been merged with web technology to allow even more audiences to access these 3D models from web browsers in the form of web scenes.

Most of the previous 3D GIS modeling projects used CAD data as the foundational data. The CAD data were converted into GIS data using GIS software. Most of the 3D software can read 2D GIS data, making it easy to utilize these data in the creation of the 3D models. However, the CAD data required scrubbing and organizing for them to be useful. For instance, Johnson (2008) used SketchUp software and CAD data to develop a 3D model for creating an evacuation plan for Montclair High School. Johnson converted CAD data floor plans into GIS data and used topology rules to implement data integrity and make the data useful for the project. The data cleanup was followed up by classification of the plans into rooms, walls, windows, doors, and pathways in 2D format. The 2D data were then converted into 3D through extrusion in SketchUp software. This enabled the use of the created 3D models in the ArcScene Application to develop the 3D model for the evacuation plan, using ArcGIS for Desktop.

Various projects implemented similar methods but used different software. Esri (2015) used Computer Generated Architecture (CGA) in CityEngine to customize building footprints and generate 3D object representations for the Esri campus in Redlands, California. Esri used CGA to develop unique codes and rule packages that characterized the 3D models of features. According to Esri, users can use the language to generate their own unique rules that extrude specific 3D features and give the custom texture. The rules are then applied on 2D or 3D models to give the features the desired $3 \mathrm{D}$ representation. Esri then published the 3D campus model into a 3D web scene to make it accessible via a web browser. The web scene revealed details of the interior features of the buildings such as rooms and staircases.

Both SketchUp and CityEngine are capable of supporting the development of 3D models. Although the results from both projects are 3D models, there were some notable differences between the two software, mainly in the workflows and usability of the software for different users. SketchUp software is much easier to use than CityEngine 
because of its interactive toolbox. It is easier for users who have limited knowledge of 3D software or GIS. SketchUp does not read attribute tables in data to extrude models based on height fields, but enables extrusion through a graphical user interface (GUI) for each model. CityEngine is designed to create 3D models based on CGA rule packages assign to shapes with attribute tables. This process can be a single operation or a batch process. However, the software requires the user to have skill in CGA programing language to write a custom rule package to fit a specific project scenario.

\subsection{ArcGIS Network Analyst Extension}

ArcGIS for Desktop provides a network spatial analysis capability to solve complex routing problems (Esri, 2015). It gives full functionalities to support routing phenomena and enables users to create network datasets, perform spatial analyses, and implement data quality control measures for determining the accuracy of data for unique network requirements (Esri, 2015). Network Analyst connects edges based on network requirements and performs spatial analysis for routing needs such as drawing a routing path between two or more selected locations. It allows users to set speed limits and define and choose parameters such as one or two-way roads. And it can then determine the drive time as well as provide a route to access service areas and closest facilities.

The City of Redlands implemented a 2D project for solid waste collection vehicle route optimization to minimize the time for waste pick up (O'Connor, 2013). The City of Redlands used Network Analyst and Dijkstra's algorithm, "which is a simpler algorithm that finds the shortest or lowest cost path between two points. This algorithm preserves balance between evaluating a near optimal path to travel with one that is computationally practical. Dijkstra's algorithm divides the network dataset into lines or edges, with each edge representing a traversable or non-traversable piece of the network" (O'Connor, 2013 , p. 6). The goal of this project was to reduce the travel time cost for collecting solid waste from residential homes. The implementation methods were done by using ArcGIS for Desktop and ArcGIS Network Analyst extension. The project used both vector data and raster data to accomplish its goal. The vector data included parcel, stop signs, traffic lights, and roads. The raster data contained a DTM for the Redlands area. The final result of this project was a complete set of network datasets to help users and the city management to reduce travel time between pick up locations. This project lacked any 3D visualization and it was limited to run in the ArcGIS for Desktop environment.

\subsubsection{D Network Analyst}

Three dimensional routing in the Network Analyst geoprocessing tool (Esri, 2015) requires geometry with $\mathrm{Z}$-values. The three dimensional network is capable of real life visualization of data, unlike 2D data. However, limited spatial analyses are supported in 3D as compared to 2D data. This is due to the software capabilities for the 3D data and spatial analysis. For example, users who interact with three dimensions navigation find it easily understandable as opposed to two dimensional routing because the 2D lacks the real life mimicry. Also, the 2D data have more limitations, especially when dealing with systems that have multi-level study areas such as hospitals and hotels. In this case, the three dimensional data and analyses provided more meaningful and contextual 
information to the end users. This could be especially beneficial for indoor emergency responses and evacuations.

\subsubsection{The 3D Indoor Routing}

The GIS provides a spatial solution for creating networks and relationships among the criteria networks (Esri, 2015) that enables users to navigate from one point to another within a geographic context. Routing and navigation solutions are based on network datasets as they provide turn-by-turn capability based on the rules and relationships within these datasets. Indoor routing solutions offer these routing analyses to help users navigate from one point to another within buildings and structures such as offices and conference centers.

According to $\mathrm{Xu}$ (2014), outdoor navigation systems are no longer a difficult approach to implement as compared to 3D indoor routing. According to O'Connor (2013), there are several reasons behind the lack of needed functionality in GIS analysis, such as the limitation of affording large scale data for buildings, inhomogeneity between objects, and low positioning accuracy. Indoor routing is categorized into graphical and geometrical. The difference between these is the level of accuracy. The study conducted by $\mathrm{Xu}$ was concerned with developing an automatic method for generating indoor networks based on a Triangulated Irregular Network (TIN) using algorithms to help users create indoor networks for complex buildings. The approach of his project was to design the network and increase the effectiveness of data usage, develop a method to generate pathways in 2D floor plans inside GIS environment, and connect edges and nodes in 2D floor plans for movement purposes. This automatic method for creating indoor networks lacks the necessary accuracy when applied to different study areas.

Similarly, Han, Zhang, and Wang (2014) undertook a project where they used the Network Analyst extension to design and develop a 3D indoor routing system. The project was based on 2D vector data, a network model, and 3D scenes. The required data for creating the network dataset were road network, stair, network integration, and path. They integrated these datasets to build the most suitable 3D network for Shandong University. The project was implemented by using ArcGIS for Desktop as well as MapControl and SceneControl within ArcEngine. This application was a proof of concept for the Geomatics College building at Shandong University. This project used ArcEngine 10.0 which is no longer supported.

\subsection{Summary}

In conclusion, the 3D Network Analyst model is a solution of three dimensional routing for many purposes such as an emergency response scenario. This model allows people to display different routes scenarios between two or more locations. It was very important to create a 3D indoor routing system that had indoor features such as rooms, pathways, floor plans, and floor transitions. But the web technologies are still limited to support the 3D web routing applications. Most of these projects could run only within ArcGIS for Desktop. This limits the number of users who can utilize the solution since most of the projects used proprietary software. In addition, most of the projects used the 2D representations. This limited the usefulness of the results since they do not represent the real world. The most usual functions in the network Analyst are calculating travel time 
between locations, and providing lengths for travel paths. Most of these projects applied desktop solutions and thus lacked 3D web technologies. Some used Esri software that is no longer supported, such as ArcEngine, which could not support real-time routing functionality for optimal navigation system. 


\section{Chapter 3 - Systems Analysis and Design}

This chapter addresses the system design by providing an overview of the project components for developing the 3D indoor routing solution. Section 3.1 discusses the project problem statement. Section 3.2 focuses on requirements analysis, which consists of the functional and non-functional requirements. Section 3.3 covers the system design, which includes the software and hardware used in the project. Section 3.4 illustrates the project plan, and Section 3.5 gives a conclusion and summary of the chapter.

\subsection{Problem Statement}

With more than 37 buildings, the University of Redlands faces challenges such as the lack of three-dimensional (3D) routing tools for its campus and facilities. In addition, the University has no interactive digital map on its website, which precludes students and visitors from browsing an interactive 3D map with route results. This project addressed two aspects of the larger problem: determining optimal exit routes from one specific building, Appleton Hall, and visualizing routes within Appleton Hall in three dimensions.

\subsection{Requirements Analysis}

To deliver any successful project and meet the client needs, a requirement analysis is necessary. System requirements are categorized as functional or non-functional. The functional requirements entail the overall performance expectations of the system. The non-functional requirements are a system's technical and operational components. Table 3-1 is a list and short description of the project's functional requirements which were identified: 3D Network Analyst GP tool, Route Optimization, Indoor Network Dataset, Share Web Scene, Search Capability, Information from Pop up Window, and Screenshot Capture.

\section{Table 3-1: Functional Requirements.}

\begin{tabular}{|l|l|}
\hline Functional Requirements & Description \\
\hline 3D Network Analyst GP tool & $\begin{array}{l}\text { The Network Analyst GP tool gives the ability for } \\
\text { users to define an origin and a destination of the } \\
\text { route needed. The result will be a 3D representation. }\end{array}$ \\
\hline Route Optimization & $\begin{array}{l}\text { The system will calculate the best route for } \\
\text { handicapped and non-handicapped using either the } \\
\text { staircase or the elevator based on the user inputs. }\end{array}$ \\
\hline
\end{tabular}




\begin{tabular}{|l|l|}
\hline Functional Requirements & Description \\
\hline Indoor Network Dataset & $\begin{array}{l}\text { The system will include a complete indoor network } \\
\text { dataset of Appleton Hall. }\end{array}$ \\
\hline Share Web Scene & $\begin{array}{l}\text { Users will be able to share the web scene link via } \\
\text { social media. }\end{array}$ \\
\hline Search Capability & $\begin{array}{l}\text { Users will be able to search for building name from } \\
\text { the web scene. }\end{array}$ \\
\hline Information from Pop-Up Window & $\begin{array}{l}\text { The buildings in the web scene will provide the user } \\
\text { with more details upon click. }\end{array}$ \\
\hline Screenshot Capture & $\begin{array}{l}\text { Users will be able to capture a screenshot from the } \\
\text { web scene. }\end{array}$ \\
\hline
\end{tabular}

Seven functional requirements were identified for the two parts of the system: the routing analysis and the web scene. For the routing analysis, the system needed to calculate the best route for handicapped and non-handicapped users in Appleton Hall. Users needed to be able to define whether to calculate the route based on shortest time or shortest path, and by the methods of travel, such as by elevator or staircase. The resulting route would be in a 3D representation. Routes would also contain the estimated times to travel from one location to another. The Network Dataset represents the complete connected networks within the floor plans in Appleton Hall, and the entrances to the four surrounding buildings.

The web scene should help users visualize the resulting routes in 3D using a web browser. Users will be able to share the 3D model via common social media websites such as Twitter and Facebook. To make the usability of the web scene more intuitive, a search capability was included. A user can enter a building name and the entered building is selected and highlighted in the web scene, as well as a pop up window showing the building details. The building details include: building name, building code, description, and picture. The Screenshot Capture functionality will allow users to download and print particular views from the web scene.

The Non-Functional requirements addressed the technical, operational, and transitional functions to support the project functional requirements. These nonfunctional requirements performed the background processes that supported the analysis 
for the routing tool. Table 3-2 is a list and description of the project non-functional requirements that were addressed: Operating System, Esri ArcGIS for Desktop 10.3, CityEngine 2014.1, Publish the web scene, File Geodatabase, Coordinate system, and File format.

Table 3-2: Non-Functional Requirements.

\begin{tabular}{|c|c|}
\hline Non-Functional Requirements & Description \\
\hline Operating System & $\begin{array}{l}\text { Windows } 8 \text {, Processor Intel (R), } 64 \\
\text { operating system, } 8.00 \text { GB RAM }\end{array}$ \\
\hline Esri ArcGIS for Desktop 10.3 & $\begin{array}{l}\text { ArcGIS for Desktop version } 10.3 \text { was used } \\
\text { as the GIS platform with a focus on the } \\
\text { Network Analyst extension. The platform } \\
\text { was used for geodatabase design, data } \\
\text { editing, and network analysis. }\end{array}$ \\
\hline CityEngine 2014.1 & $\begin{array}{l}\text { CityEngine version } 2014.1 \text { was used to } \\
\text { design, customize, and extrude } 3 \mathrm{D} \text { objects } \\
\text { by applying rule packages written in the } \\
\text { CGA programming language. }\end{array}$ \\
\hline Publish the web scene & $\begin{array}{l}\text { The web scene was published using } \\
\text { CityEngine and hosted in CloudCities. } \\
\text { CloudCities is a web scene viewer designed } \\
\text { to host scenes based on the CityEngine } \\
\text { format for viewing by public users. }\end{array}$ \\
\hline File Geodatabase & $\begin{array}{l}\text { A file geodatabase was designed in the } \\
\text { ArcCatalog application to organize the } \\
\text { network dataset and all other feature } \\
\text { classes. }\end{array}$ \\
\hline Coordinate system & $\begin{array}{l}\text { The NAD 1983_StatePlane California V } \\
\text { FIPS } 0405 \text { Feet coordinate system was } \\
\text { used to design the file geodatabase. }\end{array}$ \\
\hline File format & $\begin{array}{l}\text { All the final data are in a common GIS file } \\
\text { geodatabase format. }\end{array}$ \\
\hline
\end{tabular}




\subsection{System Design}

The system design for this project consisted of five principal components: Data Processing, Geodatabase, 3D Model, Analysis, and the Web Scene (Figure 3-1).

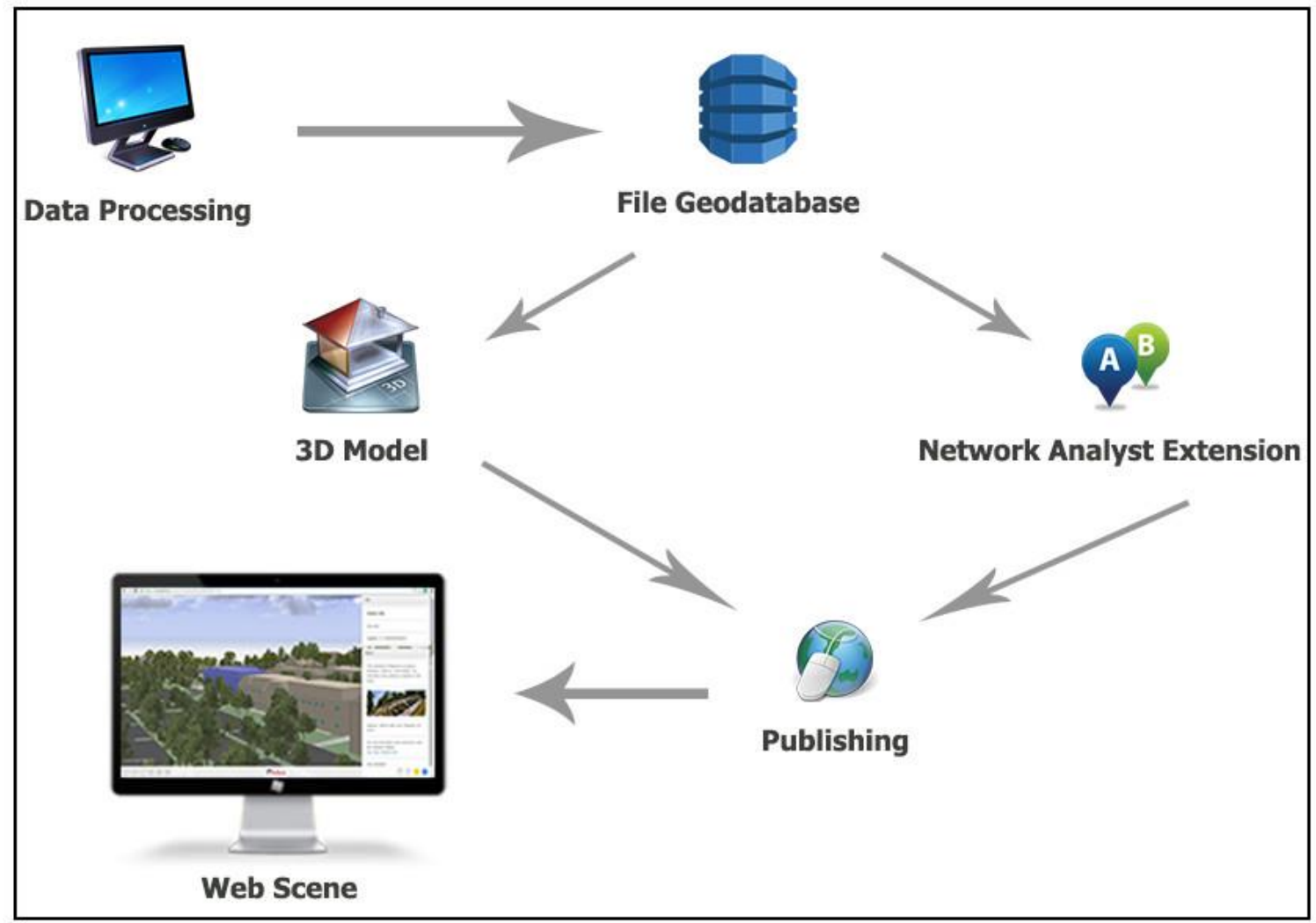

Figure 3-1: System design.

The data processing component comprised data conversion, enhancement, and editing within the ArcGIS for Desktop 10.3 platform. These data were organized in the File Geodatabase design based on the project needs via the ArcCatalog application. The Network Dataset created was hosted in the file geodatabase. This network included several feature classes, such as pathways, floor transitions, and junctions in the network. The 3D model was generated and customized using CityEngine version 2014.1. This model was built by applying rule packages and symbolizing the scene to mimic the reality as closely as possible. In the ArcScene application, the 3D network GP tool was used to generate routes between points within the network. Some sample results were published as 3D scenes to illustrate the generated routes. The CloudCities web viewer was used to host the web scene and share it with the public via a web browser. 


\subsection{Project Plan}

This project consists of five phases: Initiation, Design, Development, Deployment, and Closing. Figure 3-2 illustrates the project plan overview.

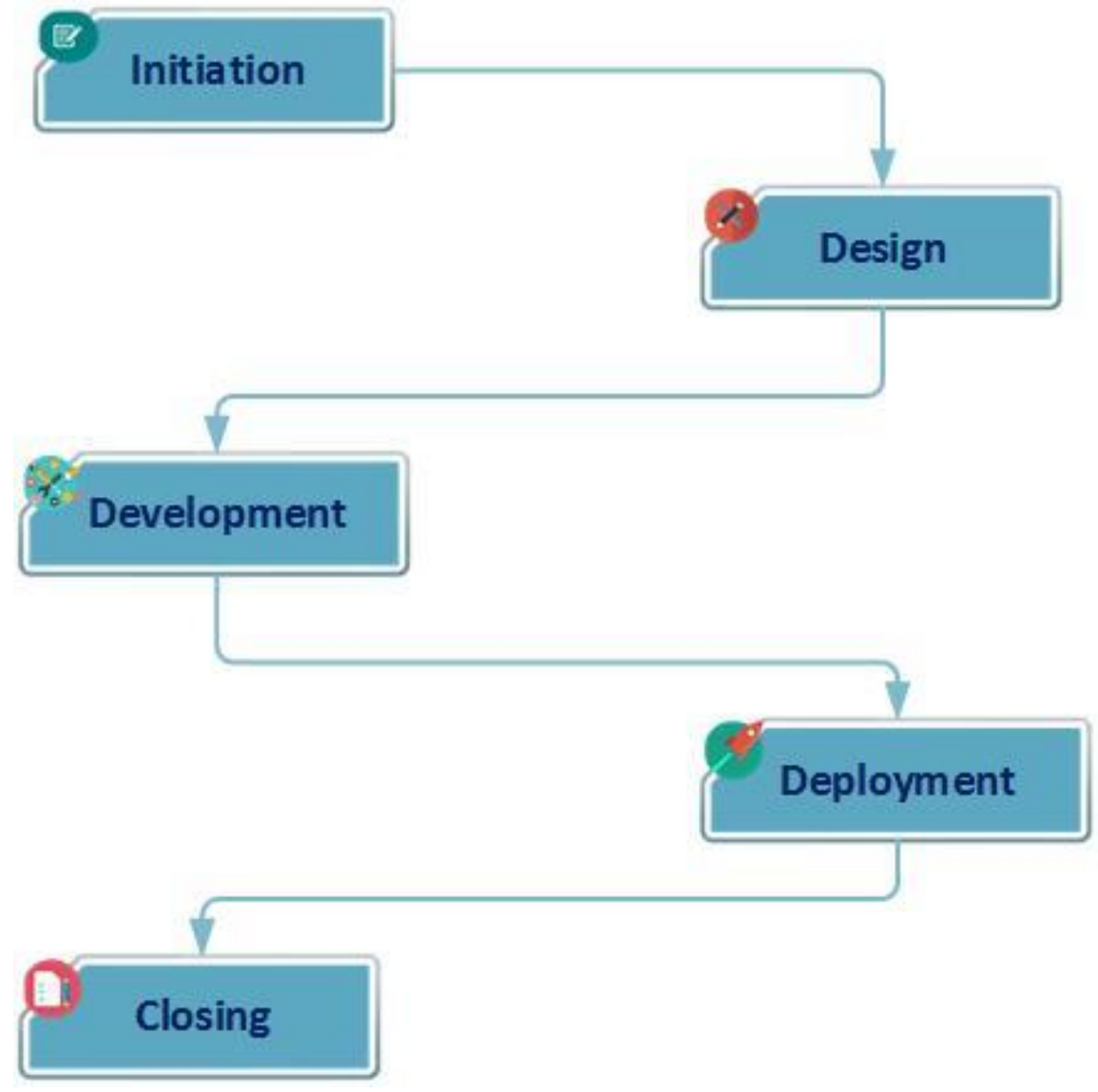

Figure 3-2: Project phases.

Each phase consisted of various tasks determined before the project started. The project initiation defined the project scope, goal, objectives, and project study area. This project relied on understanding the project area, examining data, and designing a file geodatabase which was completed in the project design phase. The development phase began by setting up the final geodatabase, testing the 3D routing GP tool, and publishing the $3 \mathrm{D}$ web scene to a web browser. After the development phase, the project moved into deployment which involved testing and examining the 3D geoprocessing tool and the web scene. The project client played a key role in testing the various functionalities of the project to ensure the goal was met. Finally, the closing phase comprised completing the project documentation, including metadata and the project report. The period of performance for this project was from May to December 2015. 


\subsection{Summary}

This chapter addressed the system implementation, requirements analysis, project design, and plan. The system requirements supported the project workflow to achieve the project results. In addition, this chapter covered the phases and tasks in each phase of this project. 


\section{Chapter 4 - Database Design}

This chapter discusses the database spatial relationships that represent the spatial relations of the project elements and objects. The database spatial relationships are explained by the conceptual data model (Section 4.1) and logical data model (Section 4.2). The chapter also explains other database related topics, including data collection methods and resources in Sections 4.3 and 4.4, respectively. Data scrubbing and loading procedures are discussed in Section 4.5. Section 4.6 summarizes the chapter.

\subsection{Conceptual Data Model}

The conceptual data model addressed the relationships between spatial components for the 3D indoor routing model. This conceptual model was needed in order to illustrate how various components relate to one another for the project's bigger picture. These components are the environments for operating the model and the inputs that the model requires.

The model had two conceptual environments of operation: web and desktop environment. The web environment in the conceptual model shows the browser side operation environment. Novice GIS users can visualize the model sample results in the form of a web scene. The desktop environment shows the functional environment where GIS professionals can input parameters within ArcGIS for Desktop and run the model to get live results.

The other component of the conceptual model was the model inputs. To successfully set up and have a functional model, various inputs were required. These inputs were categorized into two major classes: Basemap and Network. The Basemap component contained raster and vector datasets. The raster dataset included an orthophoto and a digital terrain model (DTM). The vector dataset was comprised of building footprints, trees, and pathways. The Network component of the inputs consisted of transitions, routes, junctions, and stops. Figure 4-1 illustrates the conceptual model used for this project. 


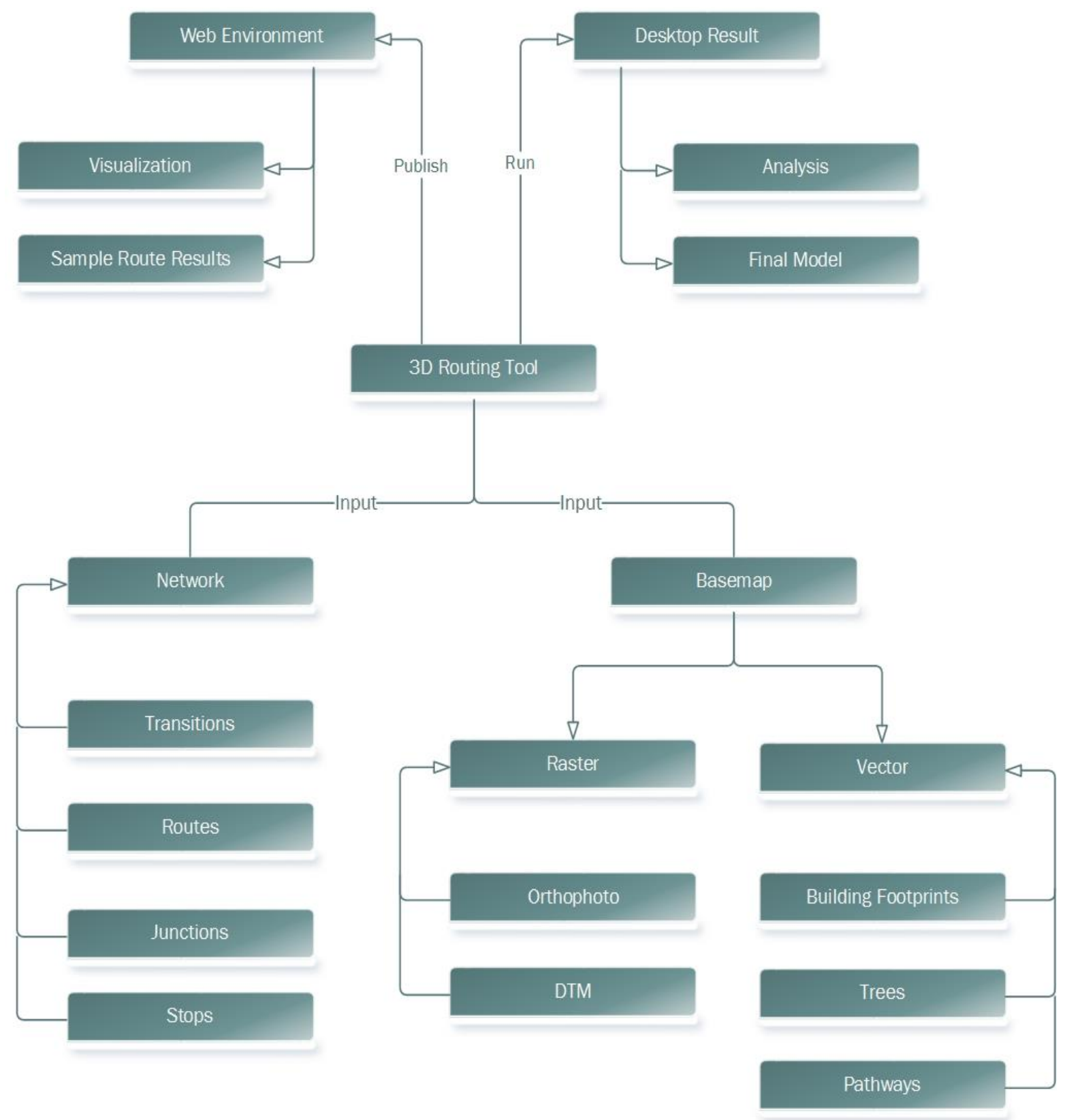

Figure 4-1: Conceptual Model. 


\subsection{Logical Data Model}

The logical model detailed the geodatabase structure of the project. This model describes the feature classes and tables for the 3D routing project and illustrates the structure and relationship between the geodatabase entities. This includes all the feature datasets, feature classes, and attributes necessary for the 3D routing model. A network needed to be built and the environments set up to allow the tool to run and produce the necessary routes. The logical model explains all components of the project database.

All data were organized in a file geodatabase, which contained three main feature datasets: Transportation, Basemap, and Analysis. The first dataset, Transportation contains various feature classes: Junctions, NFinal, Outdoor, Indoor, Floor Transition, Rooms, and Topology. The Junction is a point feature class that represents intersections across the network. The NFinal is a linear connectivity of all the junctions across the area of interest. The Outdoor is a polyline feature class that connects all the buildings in the study area. The Indoor is a polyline feature class that represents the access paths to the rooms inside Appleton Hall. The Floor Transition is a polyline feature class that provides the connectivity between building floors. These transitions include elevators and staircases. Rooms is a point feature class used to represent rooms inside Appleton Hall. Topology is a set of rules that govern the connectivity of the entire network. These are the Transportation components.

The Basemap database included nine feature classes: Surface, Trees, Building Footprints, Appleton Hall floor 1, Appleton Hall floor 2, Appleton Hall floor 1 boundary, Appleton Hall floor 2 boundary, Appleton Hall floor 1 boundary doors open, and Appleton Hall floor 2 boundary doors open. The Surface polygon feature class was used to represent the classified fields like roads, pathways, parking lots, and green areas. The Trees point feature class was used to show the location of trees on the Campus. The building footprints polygon feature class was two dimensional (2D), but included all the necessary attributes for extruding it to a 3D model used in the final model. This feature class, building footprint, had subtypes for the different roof styles including flat, shed, mansard, mansard and shed, gable, hip, gambrel, cross hipped, and cross gabled. Both Appleton Hall floor 1 and 2 used the polygon feature class to classify the interior space usage. The boundaries feature classes for floor 1 and floor 2 illustrated the exterior and interior walls as well as exterior and interior doors and windows. The open doors feature classes was a sign of an open door for the building. These are the components of the Basemap dataset.

The third dataset was Analysis, which hosted all the published route scenarios. This dataset included feature classes like RouteIndoorToOutdoorByStaircase, RouteIndoorToIndoorByStaircase, and RouteIndoorToOutdoorByElevator. These routes had attribute tables to show the walk time in minutes and how many stops were selected. Moreover, the file geodatabase hosted two raster datasets-Digital Terrain Model (DTM) and orthophoto-for the campus area. Figure 4-2 illustrates the logical model used for the project. 

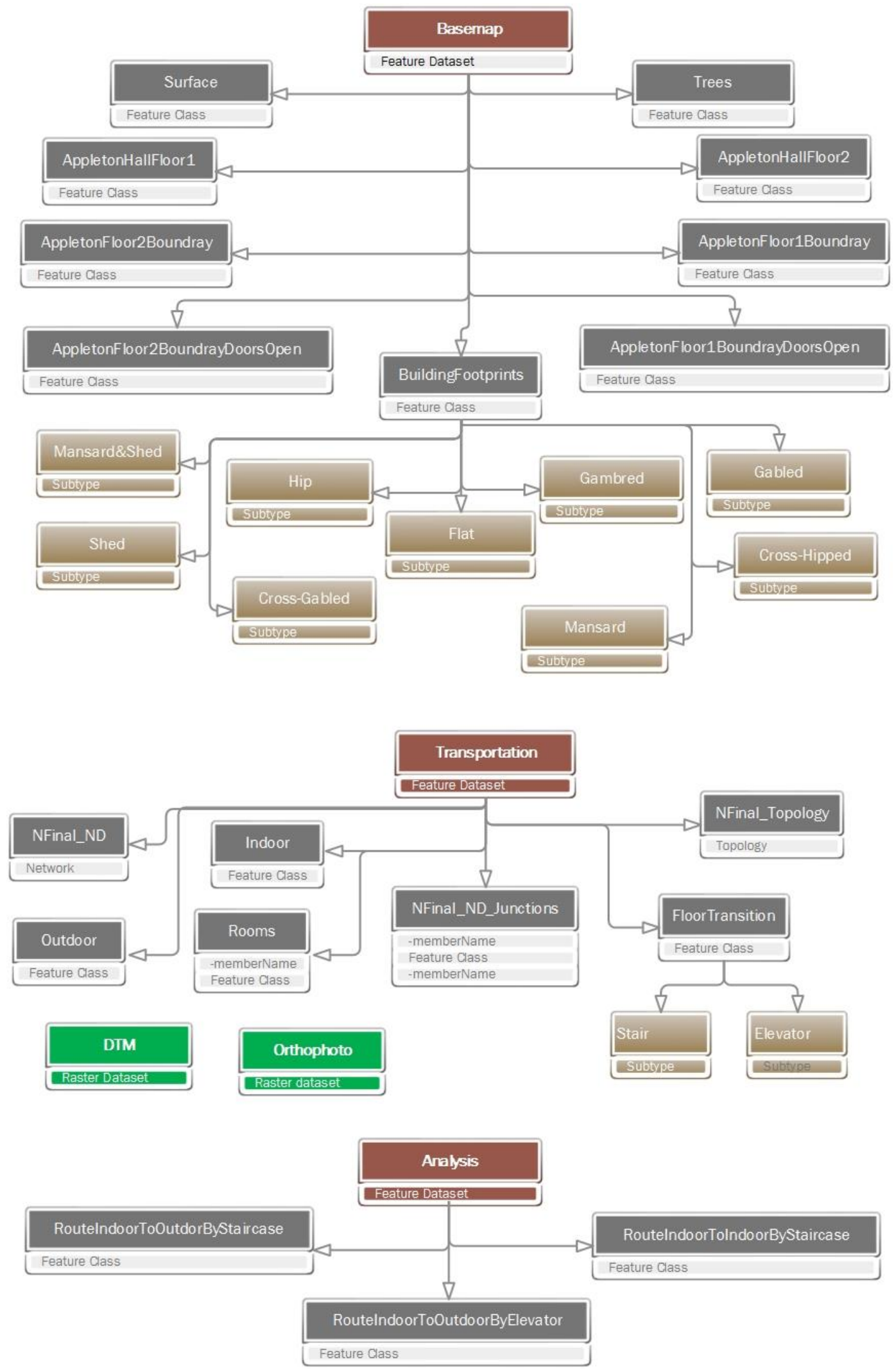

Figure 4-2: Logical Model. 


\subsection{Data Sources}

This section highlights the sources of the data used in the project. Most of the project data were provided by four sources: The University of Redlands Facilities Department; the Center for Spatial Studies in U of R; the MS GIS Program in the U of R; and the United States Geological Survey (USGS). Since the data were not already 3D-ready, processing was required to include and enhance the attributes of the various datasets. This was done to ensure that the data can have attributes like height that could be used to extrude it to make it 3D ready for the analysis. The data processing is described in Section 4.5.

\subsection{Data Collection Methods}

This section explains the methods used to acquire the project data. First, the Facilities Department data were provided on a flash drive. The data from the Center of Spatial Studies were obtained from a network connection to the central repository within the University of Redlands. The MS GIS data were availed via a Virtual Machine at the University of Redlands. Finally, the data from the USGS were download from the USGS website. Getting the information required enhancement of the obtained data and also of the purposes of ground truthing. A field visit was conducted to collect this information. For the ground truthing exercise and field visit, a printed map was used to verify the data. The other information, such as height measurements, were obtained using a tape measure.

\subsection{Data Scrubbing and Loading}

This section involves the procedures for transferring the data into the project data database. Most of the data were delivered by different sources in different file formats, which needed to be transferred into the file geodatabase. The data scrubbing and loading involved three phases: organizing, uploading, and transferring data into the file geodatabase. The organizing phase required minimal processing for setting up datasets and subtypes in the file geodatabase. For the data that needed more attributes, the Add Field geoprocessing tool was used to create new fields. For instance, a height field was added to the building footprints feature class and the height information was calculated into this height field using LiDAR data. It was necessary to set a common spatial reference for all the data. The coordinate system chosen was NAD_1983_StatePlane_California_V_FIPS_0405_Feet. The file geodatabase adopted an Esri schema, which was used in the final database. All the data were made to comply with this schema in the database. Some data, such as the building footprints, were in $\mathrm{CAD}$ format. These data were converted to feature classes and transferred into the geodatabase.

\subsection{Summary}

This chapter discussed the project database development workflows. The conceptual data model in Section 4.1 explained on the relationships between the different entities of the project database. The logical data model in Section 4.2 described the final physical geodatabase design based on the conceptual data model. Sections 4.3 described the 
project data sources. Section 4.4 explained the collection methods. Data scrubbing and loading procedures were described in Section 4.5. 


\section{Chapter 5 - Implementation}

This chapter explains the implementation process for the 3D Indoor Routing for the University of Redlands project. It covers all the procedures which were used in creating and optimizing the routing analysis, as well as the 3D model. The implementation of this project was broken into three parts: data creation, 3D indoor routing analysis, and 3D modeling. Each part of the project was implemented individually.

This chapter is divided into four sections: Data Creation (Section 5.1), which involves the data digitizing, converting, and cleaning. Section 5.2 includes the 3D indoor routing analysis, which explains the creation and building of the network dataset, and setting up attributes by querying the restrictions and walk time routes. Section 5.3 covers the modeling workflows, which encompass conversion of 2D data into 3D models. This chapter concludes with a summary in Section 5.4.

\subsection{Data Creation}

To enable the aggregation of all the data into a central database, a file geodatabase schema was necessary. This enabled loading of data from the different sources into a common standardized database following defined rules and design. This data creation was accomplished via five procedures: data conversion, feature class entertainment, LiDAR data configuration, orthophoto processing, and topology rules.

\subsubsection{CAD Data Conversion}

This stage was undertaken in order to standardize and store all the different data formats into a file geodatabase using a common format: feature classes. The project data for Appleton Hall floor plans were obtained in CAD format. It was necessary to convert the CAD data into feature classes. Since the CAD data did not have any spatial reference, the Define Projection tool was used to outline the spatial reference for the floor plans. After defining the spatial reference, the data did not align properly in the desired geographic placement. Thus, georeferencing was required to ensure the data overlaid at the correct location of Appleton Hall. The georeferencing toolset in the ArcMap application was used to georeference the floor plan's feature class using the building footprints feature class as an underlying feature to represent the truth on the ground. The building footprints feature class was chosen since it provides the best accuracy as compared to the available orthophoto. Four control points were identified on the floor plans and the corresponding points on the building footprints feature class. The georeferenced floor plan was adopted as the correct feature class in the final geodatabase. Figure 5-1 shows the georeferenced floor plan feature class. 


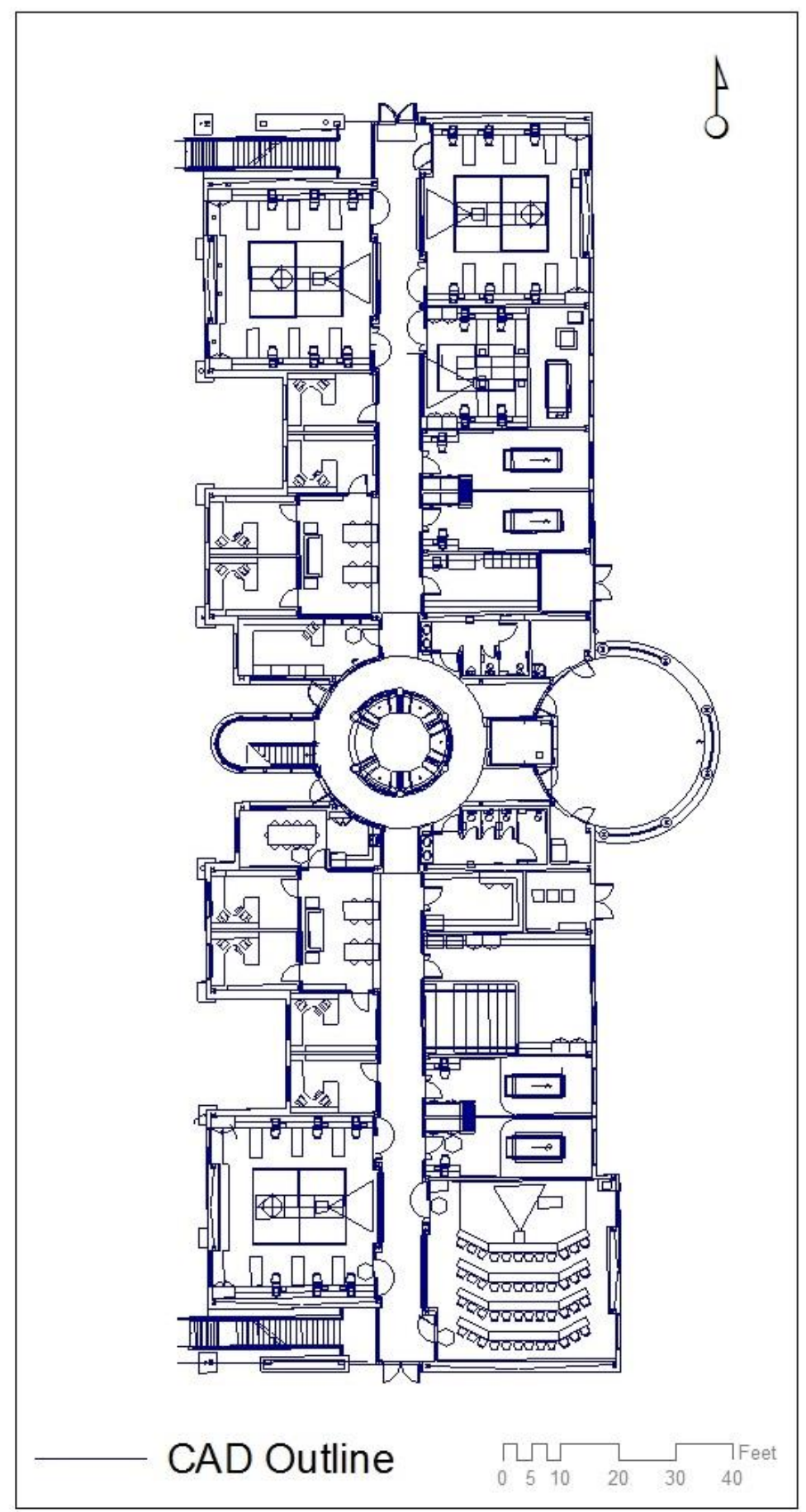

Figure 5-1: Converted CAD data floor plan of Appleton Hall into a Feature class. 


\subsubsection{Feature Class Enhancement}

The data obtained were not available in both attribute tables and features. Some important features were missing from the feature classes. Thus, some feature classes needed to be enhanced for completion and to reflect the true situation as is on the ground. These feature classes included: floor plans, rooms, and basemap feature classes. To enhance these feature classes, a digitizing method was used to update all the necessary features. Figure 5-2 shows the areas which had missing features and needed enhancement.

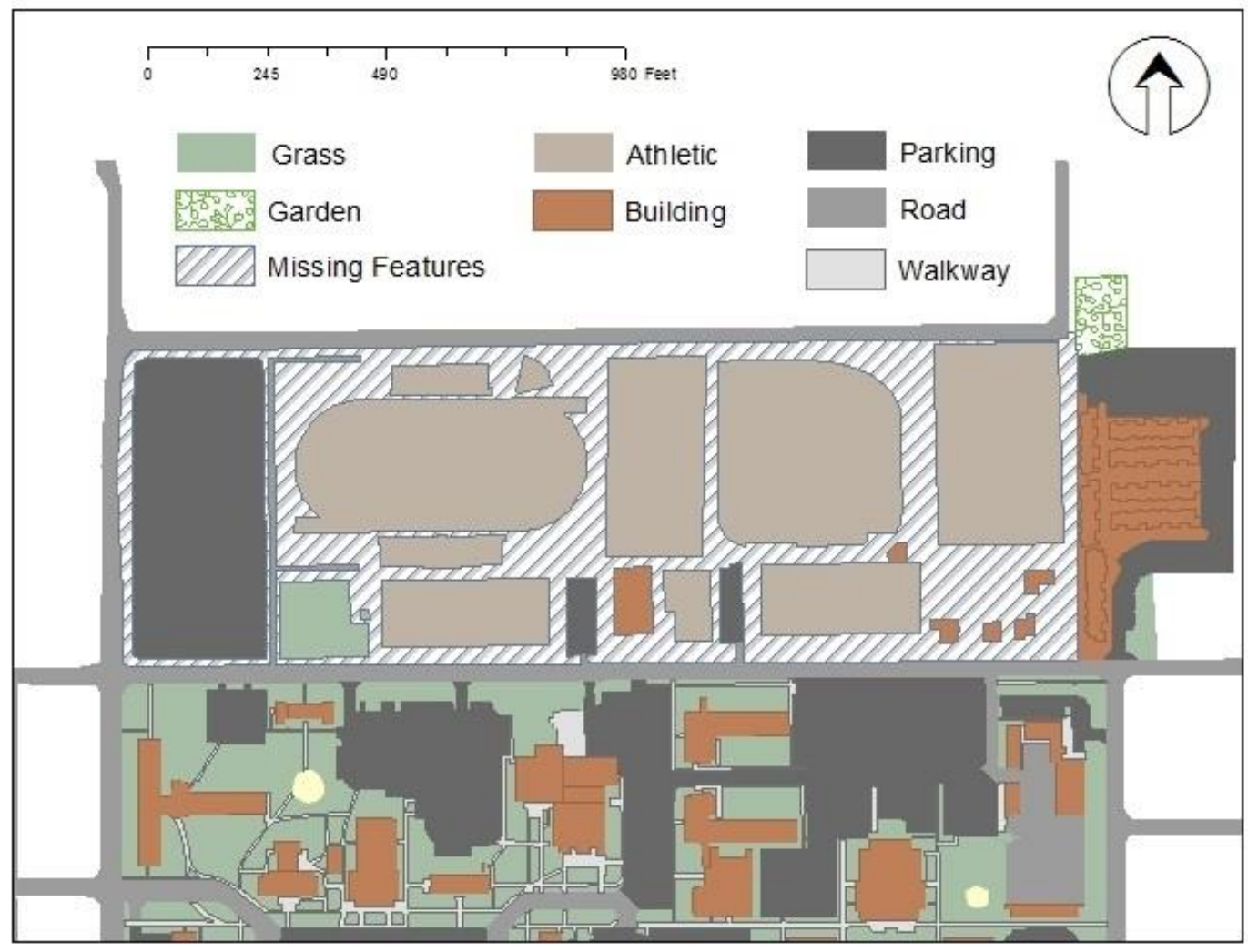

Figure 5-2: Missing features in Basemap feature class.

The CAD data that were used for creating the floor plan feature class were extremely detailed. These details were beyond the purpose of this project. Thus, a new feature class was created based on the existing floor plan to come up with a less detailed feature class to represent the floor plans. The new feature class created represented the exterior and interior walls, exterior and interior doors, and windows. The exterior walls and windows were created using buffering and offsetting methods in the ArcMap application. The buffers and offsets were processed following each room's feature class as base features. Figure 5-3 shows the new feature class that was created. 


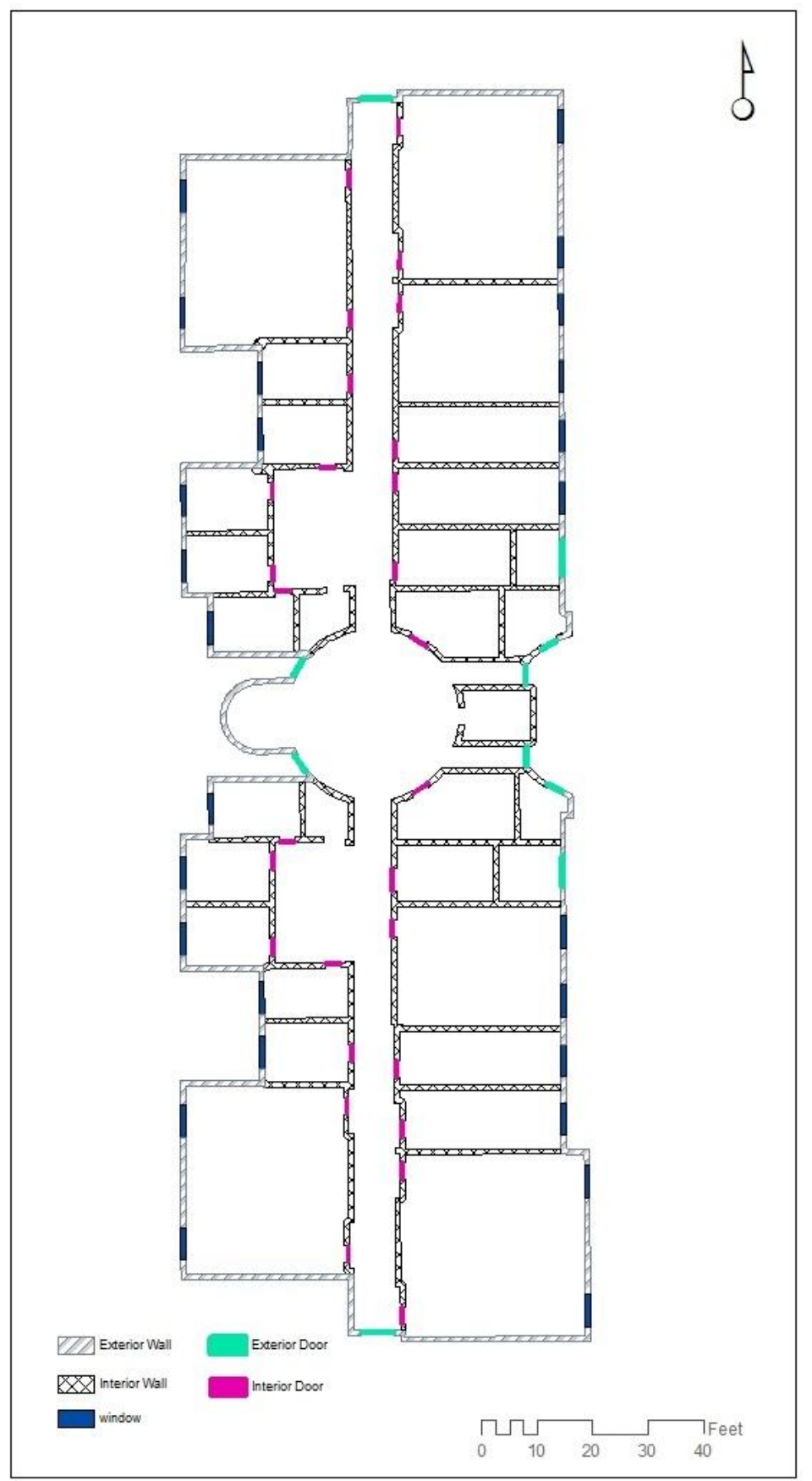

Figure 5-3: Appleton Hall First Floor Boundary. 


\subsubsection{LiDAR Data Configuration}

Some required attribution data were missing from the project data as received from the different sources. A way was required to obtain these missing attributes and build them into the respective feature class. The building footprints, the building height, roof height, and roof style attributions were required. LiDAR data were obtained to acquire these attributes for the dataset, building footprint. This was enabled by the integration of 2D profile view and 3D view of the LiDAR data. The information was extracted from the LiDAR dataset using the LAS Dataset toolset within ArcGIS for Desktop. The measurement tool within the 2D profile view was used to determine the height for the roofs and buildings. The 3D view was used to define roof styles. Figure 5-4 shows both $3 \mathrm{D}$ view and 2D profile view respectively for Appleton Hall by LiDAR data. 

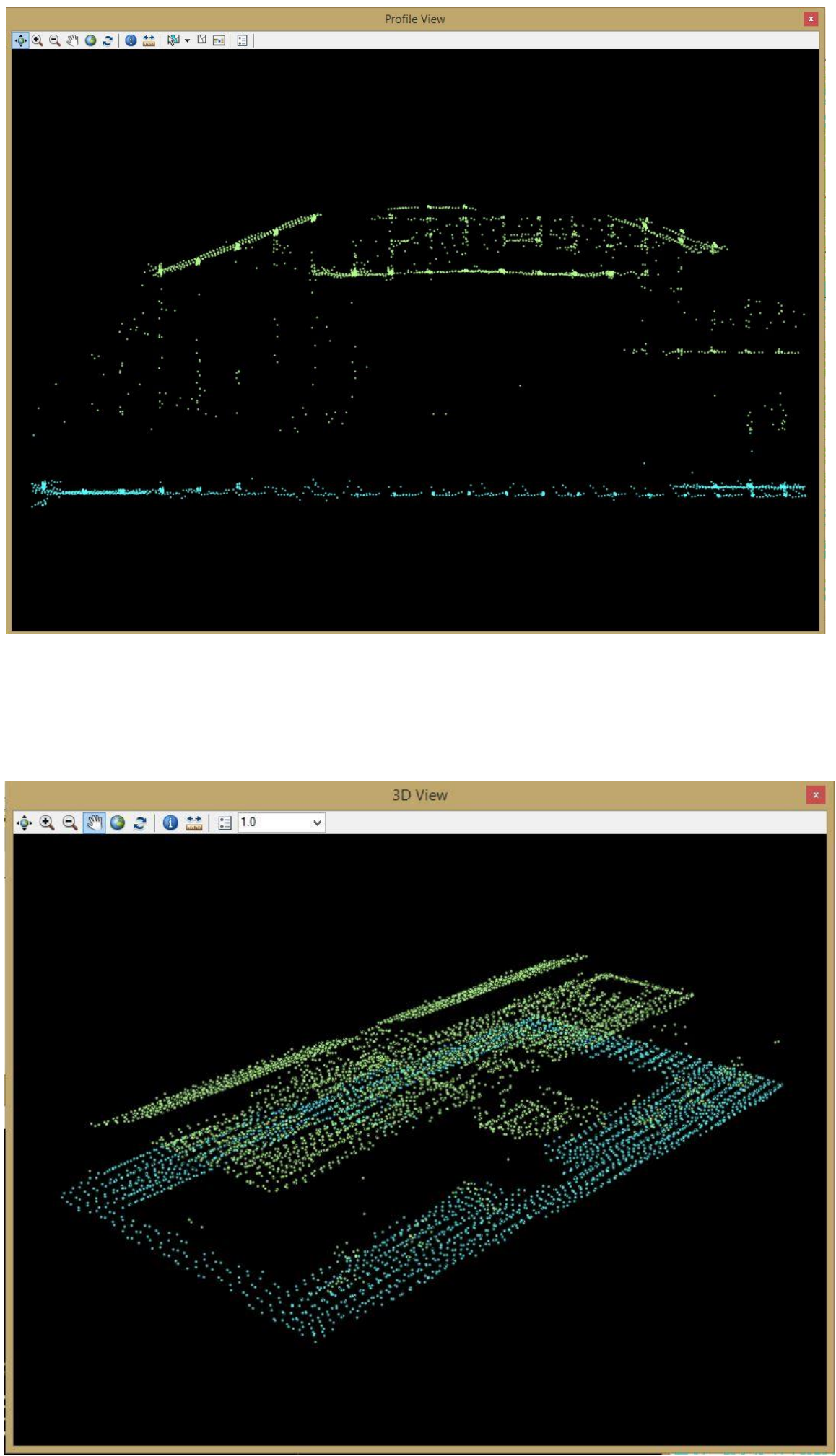

Figure 5-4: LiDAR data for Appleton Hall. 


\subsubsection{Orthophoto Processing}

The orthophoto used for the project was acquired from the United States Geological Survey (USGS). The orthophoto was acquired in four different sections since no singular orthophoto covered the whole campus. The four orthophotos were downloaded and mosaicked together to form a single orthophoto. Since the mosaicked orthophoto was beyond the required area, it was clipped to fit the campus spatial extents. Figure 5-5 highlights the final orthophoto processing. 


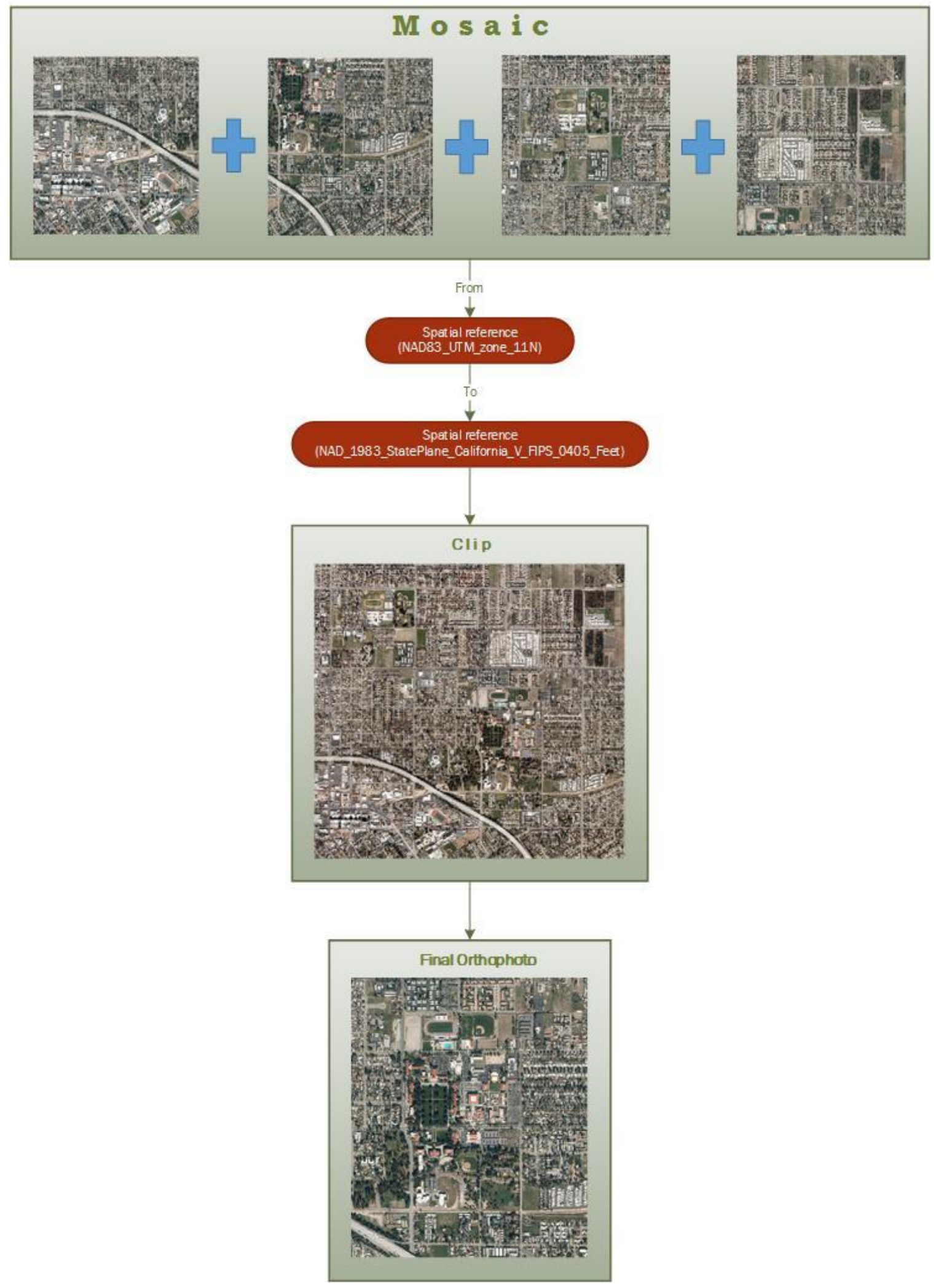

Figure 5-5: University of Redlands Orthophoto. 


\subsubsection{Topology Rules}

Topology rules were defined to govern the interactions and relationships of the data. These were set to ensure integrity and quality of the data so that the networks were well defined during the analysis. Different features needed different rules. For example, trees could not overlap parking lots and walkways, so a topology rule was set to ensure that there was no trees on the parking lots or walkways. Figure 5-6 below shows the way a topology rule was specified for different dataset.

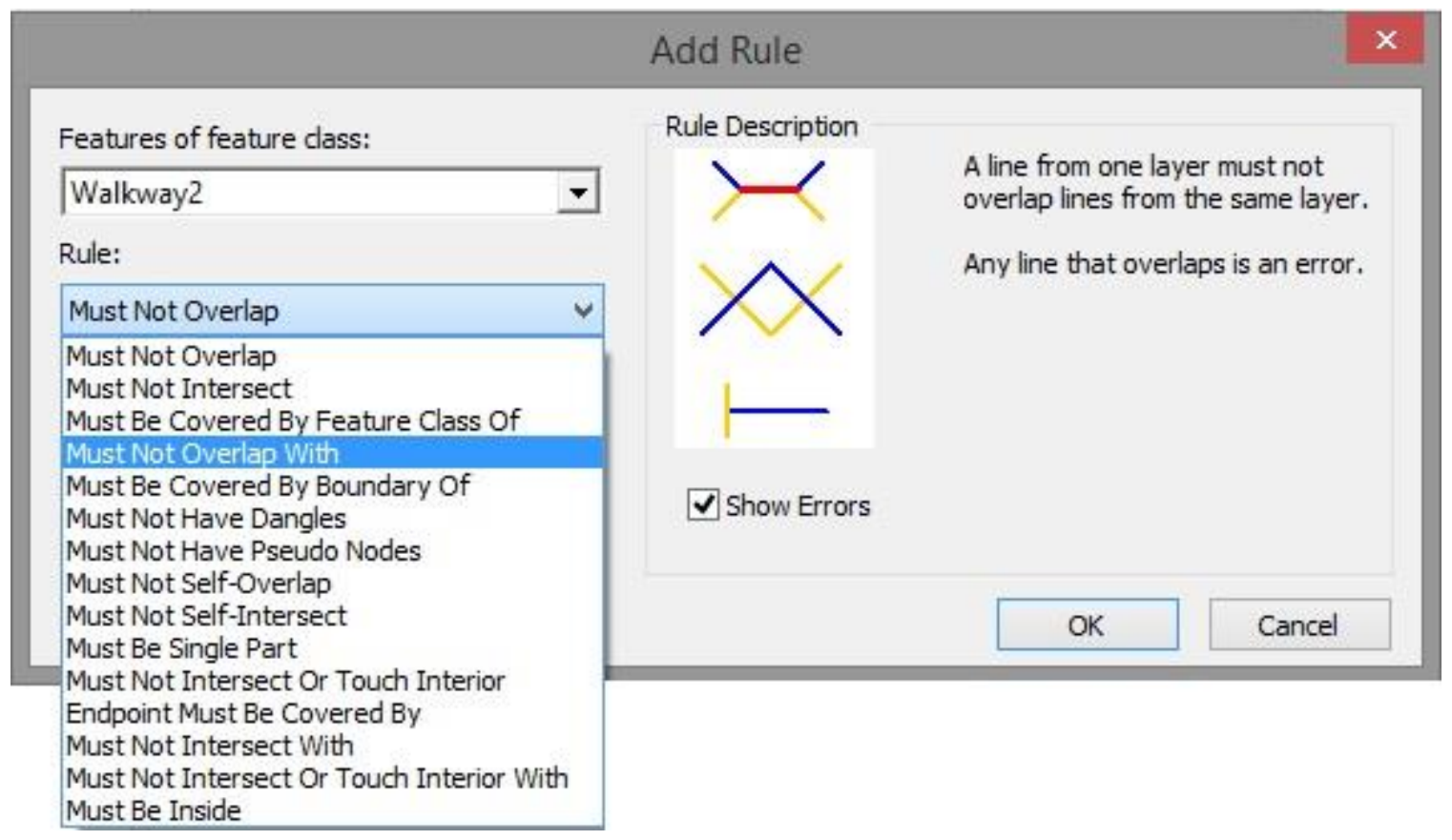

Figure 5-6: Topology rules.

After setting these rules, any data that conflicted with the topology rules were adjusted. For example, if there was a tree on a walkway, it was offset to the nearest side of that walkway.

\subsection{D Indoor Routing Analysis}

Since this was a network analysis project, the ArcGIS Network Analyst for Desktop extension was required. This enabled the Network toolset to be available for running the routing analysis. This analysis required all the necessary feature classes hosted in a network dataset. This section explains the methods which were used to set up the network environment for running the analysis.

\subsubsection{Creating Networks}

Based on the literature reviews discussed in Chapter 2, there were three ways to create an indoor network: Fishnet, Triangular Irregular Network (TIN), and Digitizing. This project 
adopted the digitizing method, which was best suited for a small study area like the one used in this project. It was also faster than the others as the project dealt with only one building with not much detail. Thus, the digitizing method was the optimal for the project. The network components digitized for this project included indoor and outdoor pathways for the study area. The indoor pathways connect the building rooms and floors, while the outdoor pathways include the paths that connect the different buildings. Figure 5-7 shows both the indoor network feature class in Appleton Hall and the outdoor network feature class. The networks were connected to each other to apply the analysis in Appleton Hall and the surrounding buildings. 


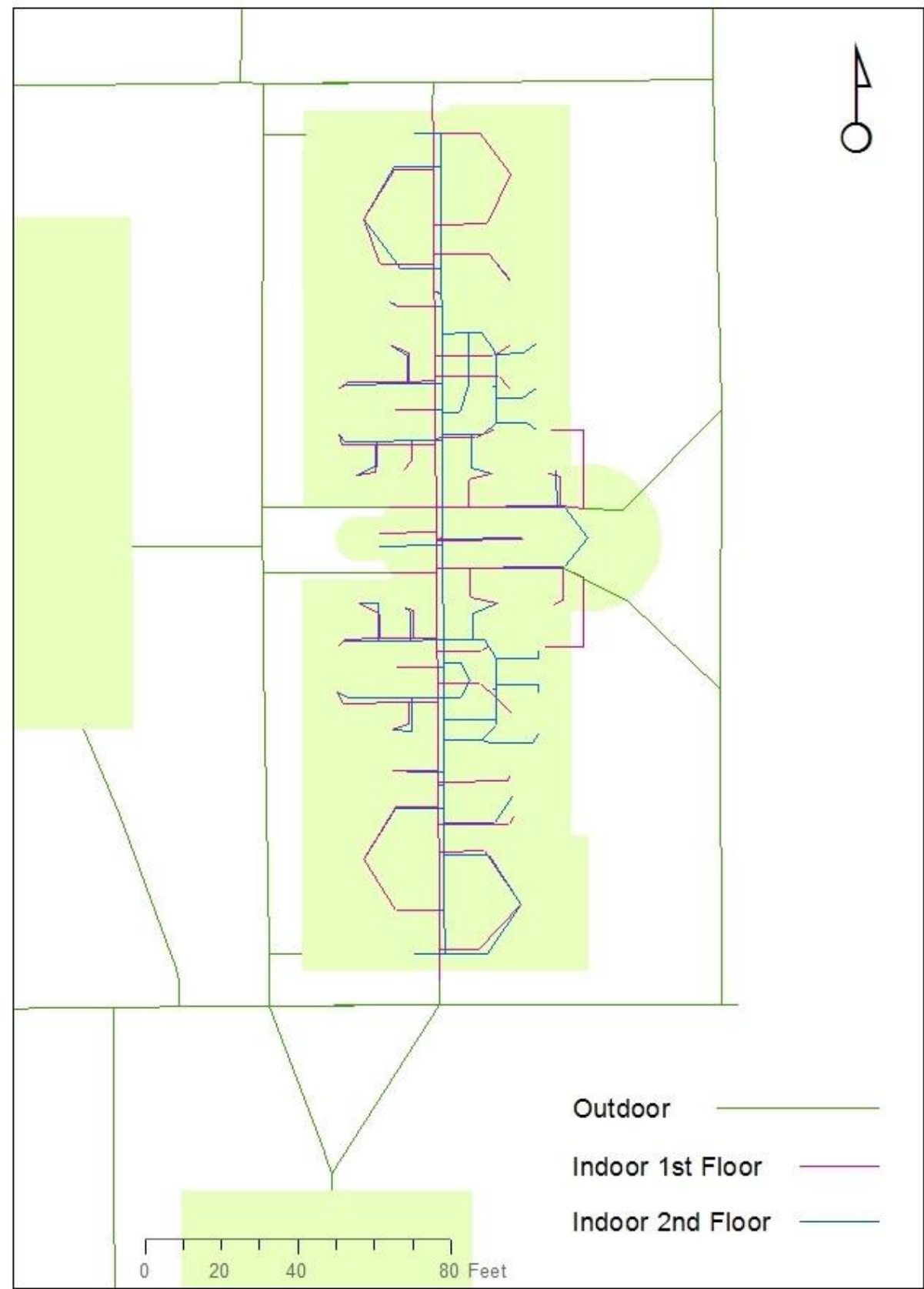

Figure 5-7: 2D views for Indoor and Outdoor network feature classes. 


\subsubsection{Building the Network Dataset}

There were three feature classes used to build the network dataset, including Floor Transitions Polyline, Indoor Polyline, and Outdoor Polyline. Figure 5-8 illustrates the workflow for creating the network dataset.

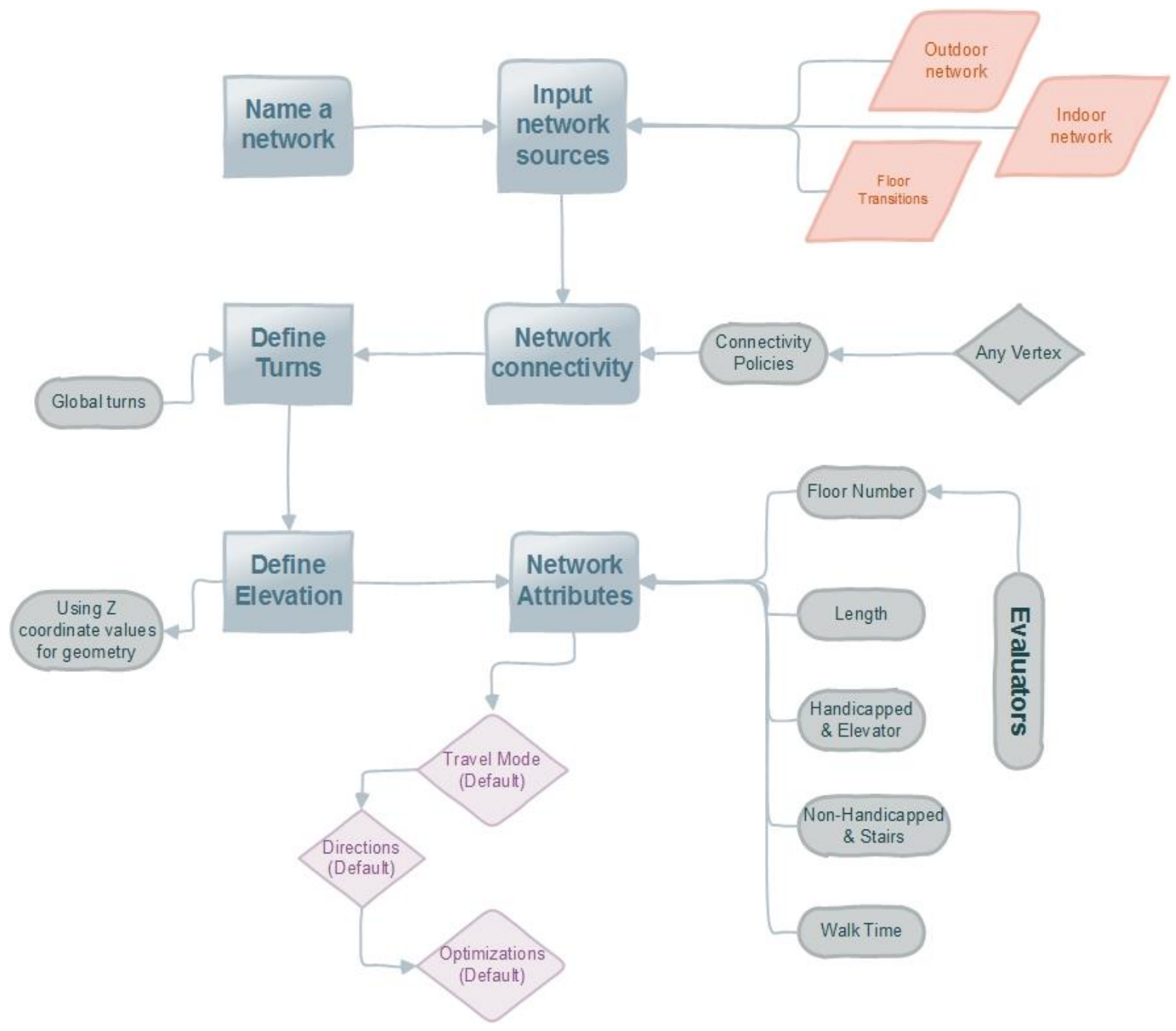

Figure 5-8: Construction Workflow for the Network Dataset.

There were nine steps to create a network dataset. The first step was providing a network name. The second step was selecting feature classes: Indoor, Outdoor, and Floor Transition. The third step was choosing the connectivity policies. For this network, any vertex was chosen. The fourth step was defining global turns chosen as default. The fifth step was using $\mathrm{Z}$ elevation values from geometry to obtain a 3D network analyst. The 
sixth step was the most important part in this workflow; defining the attributes, which were: Floor Number, Length, Handicapped and Elevator, Non-Handicapped and Stairs, and Walk Time. The Floor Number attribute was used to direct the feature classes which represent attributes From-To and To-From in the feature classes. The Length attribute was created to link all the fields which have geometry lengths. The Handicapped and Elevator, and Non-Handicapped and Stairs attributes were used to restrict the floor transition types. These attributes are described in Section 5.2.2.1. The Walk Time attribute was built to identify the estimated walk time. This is expressed in feet per minute. Section 5.2.2.2 explains the walk time method in detail. The seventh, eighth, and ninth steps used default settings in this network dataset. These were the methods of creating the $3 \mathrm{D}$ indoor routing network dataset.

\subsubsection{Restricted Attributes}

In this network dataset, two attributes were restricted based on the analysis goal. The Handicapped and Elevator evaluator was used to restrict the handicapped access to the elevators, while the Non-Handicapped and Stairs evaluator was used to restrict the nonhandicapped access to stair use. Figure 5-9 shows the query used to build the restrictions.

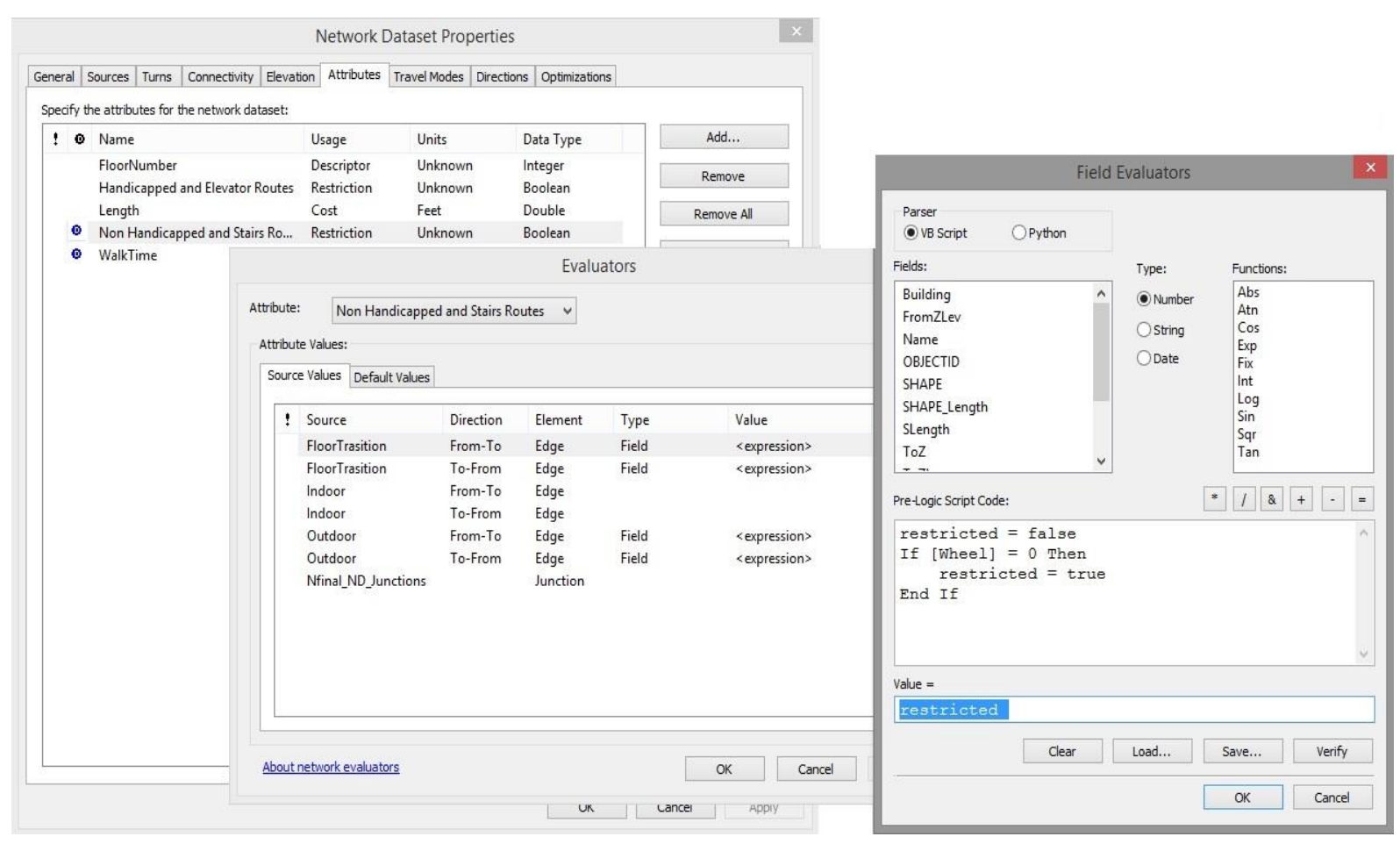

Figure 5-9: Non-Handicapped and Stairs restricted script. 


\subsubsection{Walk Time Attribute}

This Network Dataset added the Walk Time attribute, which was used to calculate estimated walk time for each route. The attribute was used to calculate different walk scenarios, such as normal walk speed, walking speed using an elevator, and walking speed using stairs. These scenarios were built by applying different expressions. Figure 510 shows the normal walk speed script used to calculate the walk time based on different equations. Since the speed used in this project utilized feet per minute, an equation was identified to implement these units. The equation Time $=\frac{\text { Length }}{\left(88^{\prime} \text { per } 1 \text { minute } * 3\right)}$ was used to convert the normal walk time from miles per hour to feet per minute. This was based on the average person's walking speed of three miles per hour. The walking speed using an elevator used the same method but the elevator speed in this case was one mile per hour. The walking speed by using stairs was two miles per hour. There are other known factors that affect the speed of people like age and slope. These factors were not factored in this project but taken as an assumption that they were constant.

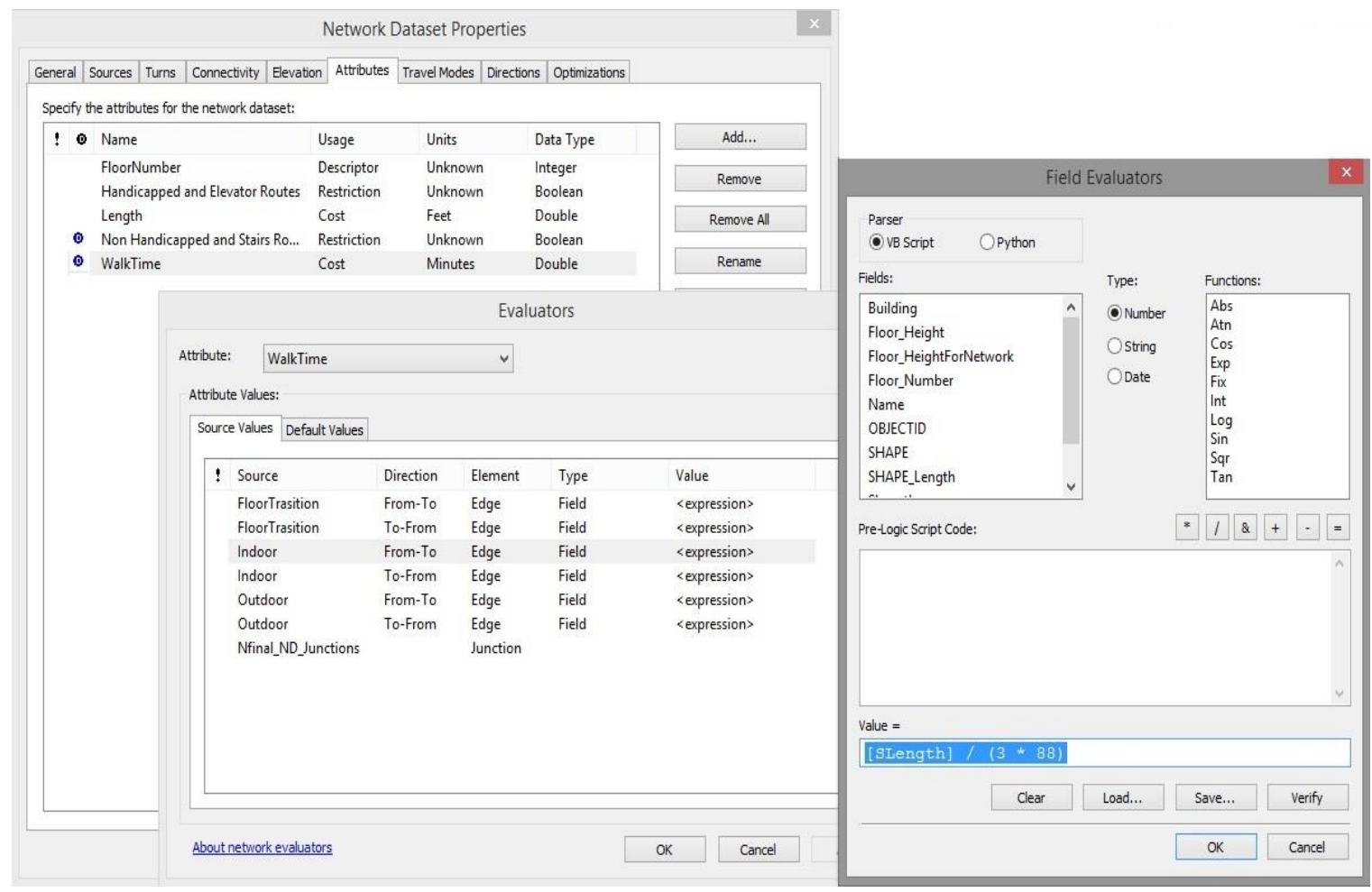

Figure 5-10: Walk Time Attribute field evaluator.

\subsubsection{Networks and Routes Errors}

The final Network Dataset was created after fixing all the errors which were not modified before building the network. These errors included network datasets that cannot operate 
curve segments and network datasets that do not accept field type Double for elevation values. Figure 5-11 shows an example of these errors.

\subsubsection{The Geoprocessing Tool}

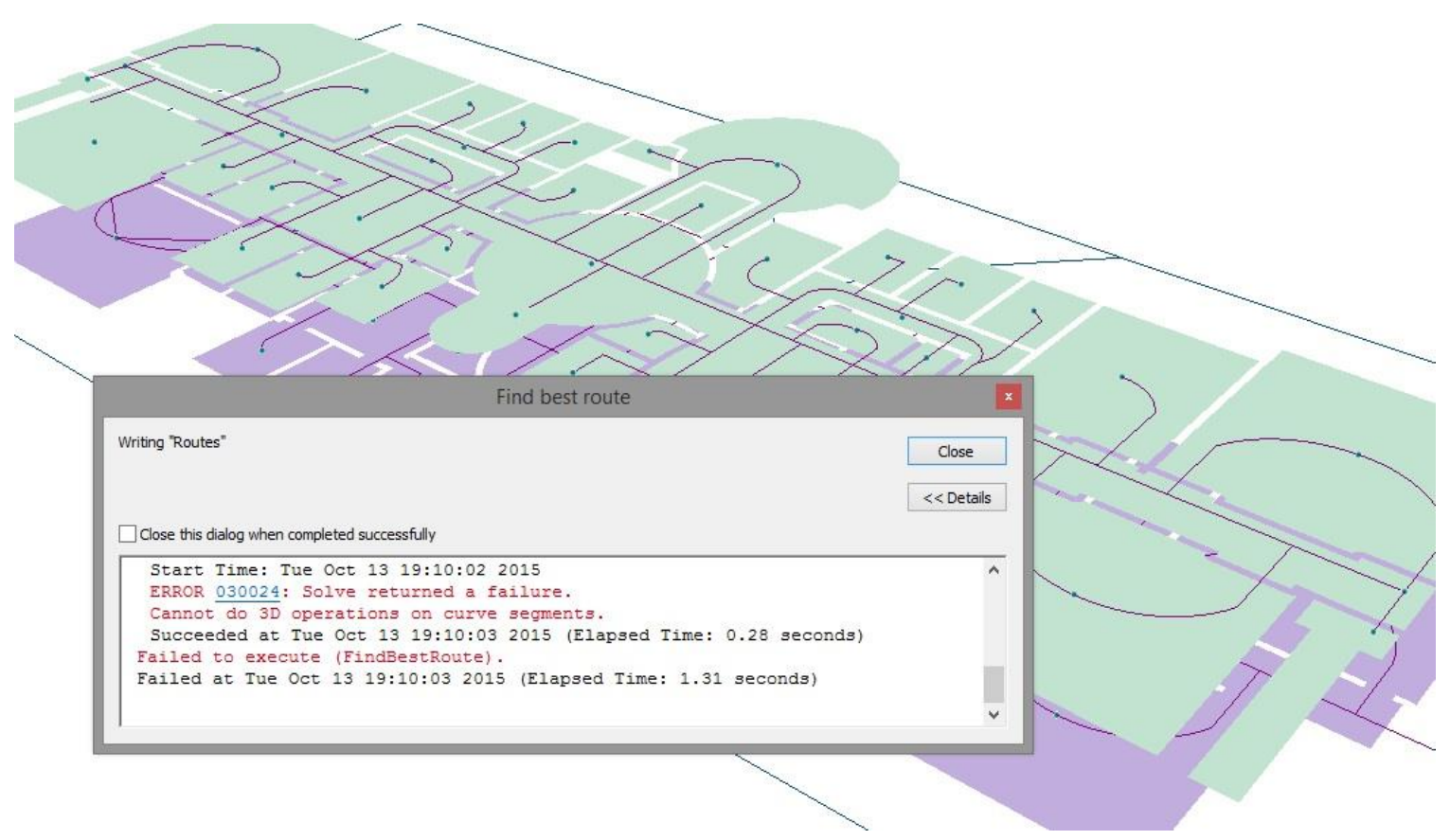

Figure 5-11: Error in operating 3D curve segments.

The 3D Indoor Routing geoprocessing tool within Network Analyst Extension to ArcGIS for Desktop was used to generate the best route in 3D based on user inputs. This tool was assigned the final network dataset, as well as modifying routes symbology. Figure 5-12 illustrates the 3D Indoor Routing GP tool in Model Builder. 


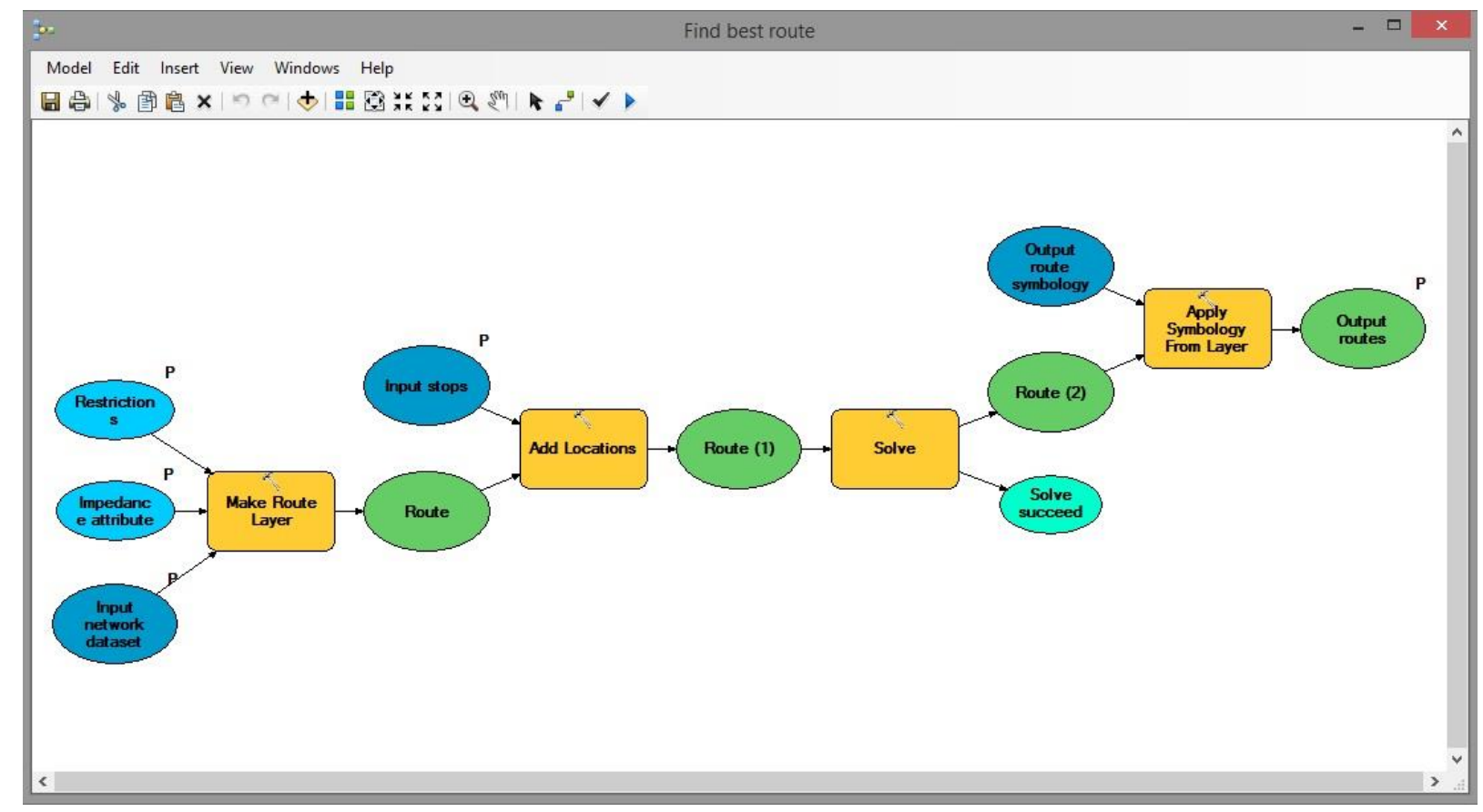

Figure 5-12: The 3D Indoor Routing Geoprocessing tool.

\subsection{D Modeling}

The 3D modeling implementation was completed by using Esri's CityEngine software. This stage involve extrusion of 2D datasets into 3D models within the CityEngine environment using rule packages. The client was fully involved in the 3D model implementation, including provision of the campus rule packages, tracking the workflow, and teaching skills and tips. The 3D modeling comprised five phases. The first phase was discussed in Section 5.3.1, and involved the creation of the new project workspace in CityEngine. Section 5.3.2 explains the Computer Generated Architecture (CGA) programming language, which was used to customize the $3 \mathrm{D}$ building extrusions. Section 5.3.3 explains the 3D modelling implementation challenges, while Section 5.3.4 addresses the uses of SketchUp software within the project. Finally, Section 5.3.5 explains the process of publishing a scene within the CityEngine environment to a web browser as a web scene.

\subsubsection{New Project Workspace}

The creation of a new project workspace is the default first step in CityEngine when a user starts a new project. This workspace hosts all the data for the project. The workspace follows a conventional framework set up in CityEngine. This framework includes subfolders like assets, data, maps, models, rules, scenes, and scripts. These subfolders contain the appropriate contents of the project as necessary. For example, the rules subfolder hosts all the necessary rule packages used for that specific project. 


\subsubsection{CGA Rule Packages}

CityEngine uses the CGA programming language as the platform for defining the rule packages used in projects. This language was used in this project to design and customize rule packages that help mimic the ground truth as accurately as possible. Using these rules, 2D data were converted into 3D models based on assigned rules and connected attribute fields. The client provided an existing rule package as a beginning point for modelling the project area. The CGA code was then customized to fit the needs of the project area. For instance, some code was included to define windows and doors for Appleton Hall (Figure 5-13).

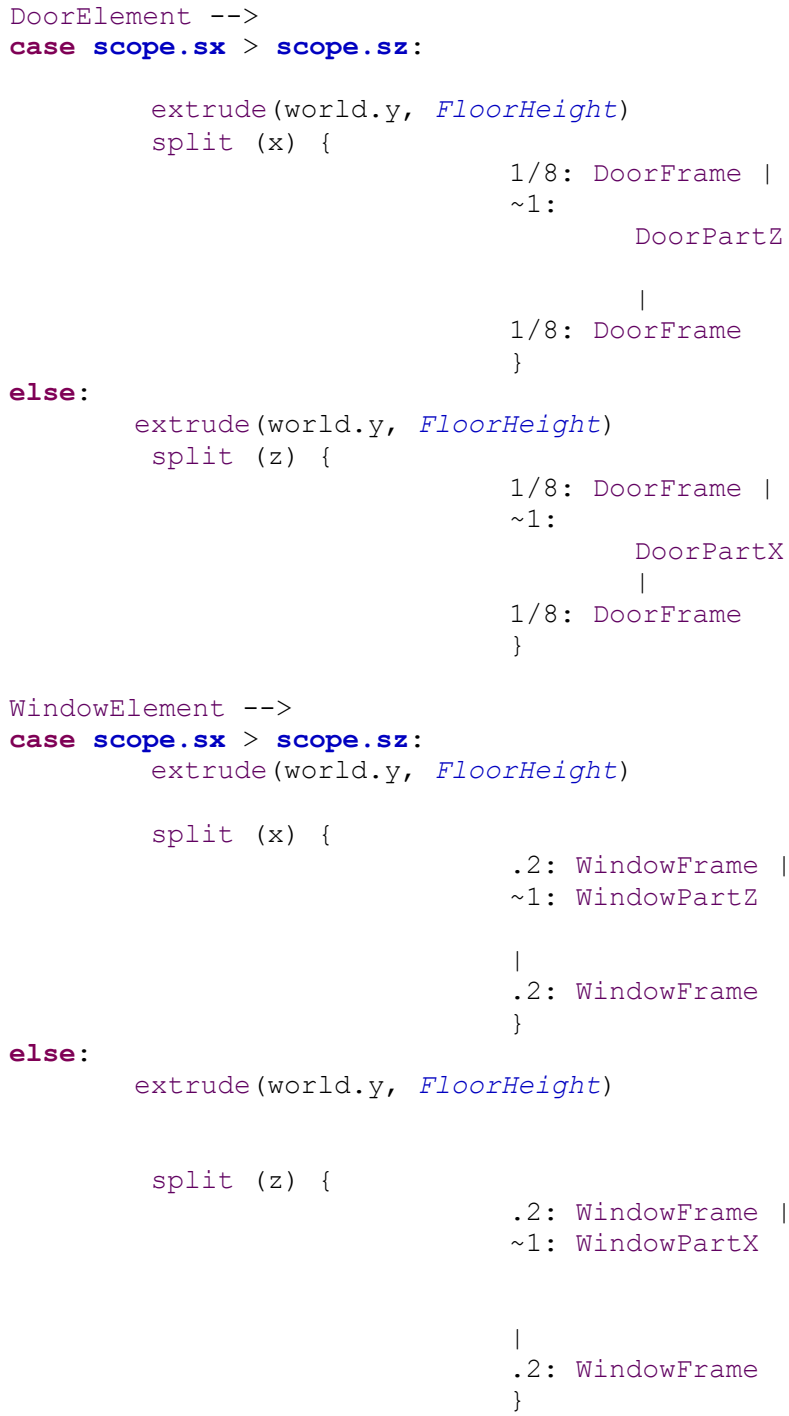

Figure 5-13: The Campus rule package defining window and door elements. 


\subsubsection{CityEngine Challenges}

Some bugs were encountered when dealing with the elevator transition. When the rule package was applied, the connection was established but the representation was not depicted visually. Figure 5-14 illustrates an example of a missing path when using an elevator.

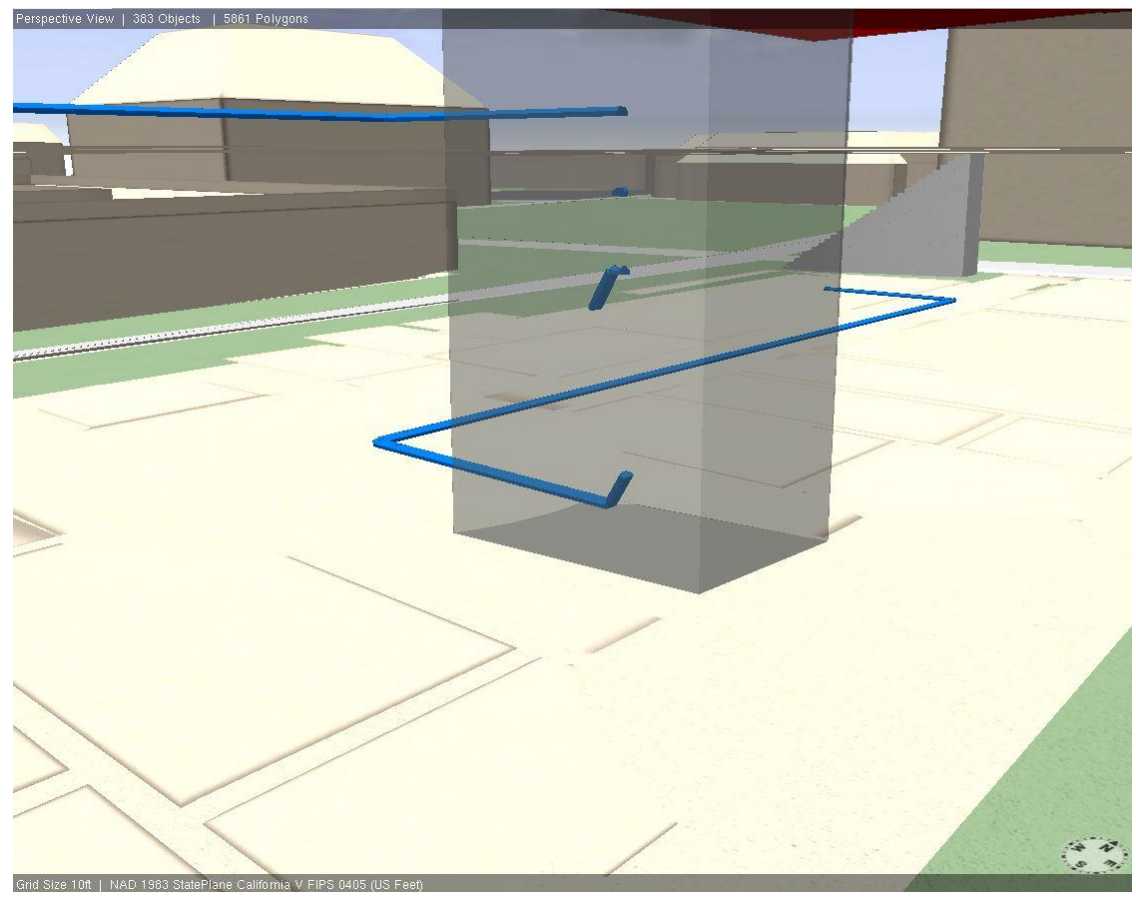

Figure 5-14: The disconnected 3D route by using elevator

This challenge was fixed by exporting the same route as multipatch format from the ArcScene application. Another challenge was cleaning up geometry after applying the rule package to the complex buildings such as Appleton Hall (Figure 5-15). This issue was fixed by using SketchUp Software. 


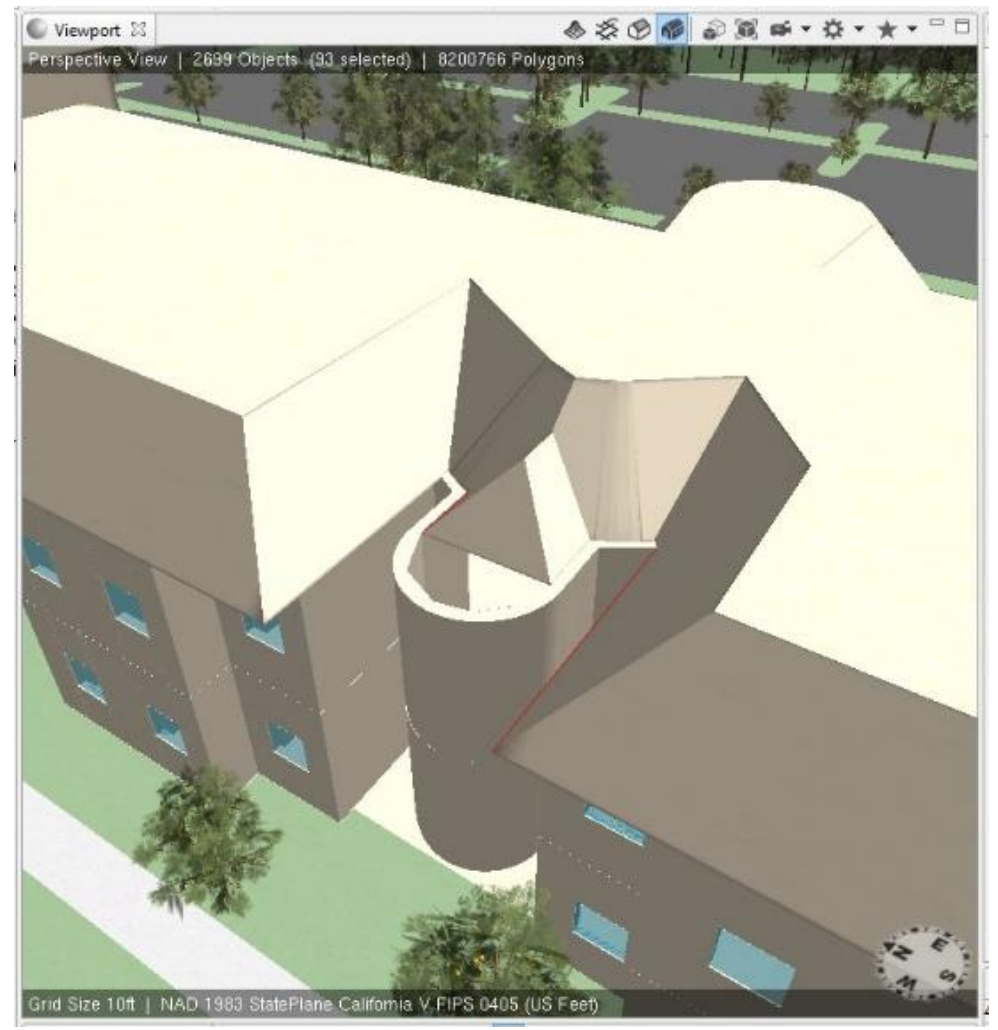

Figure 5-15: The uncompleted roof for Appleton Hall.

\subsubsection{SketchUp Editing}

Some models were not well generated in CityEngine. Therefore, these models were exported as KML file format and imported into SketchUp, which was used to correct these models, especially the roofs. The software was also used to customize both interior and exterior staircases. See Figure 5-16. 

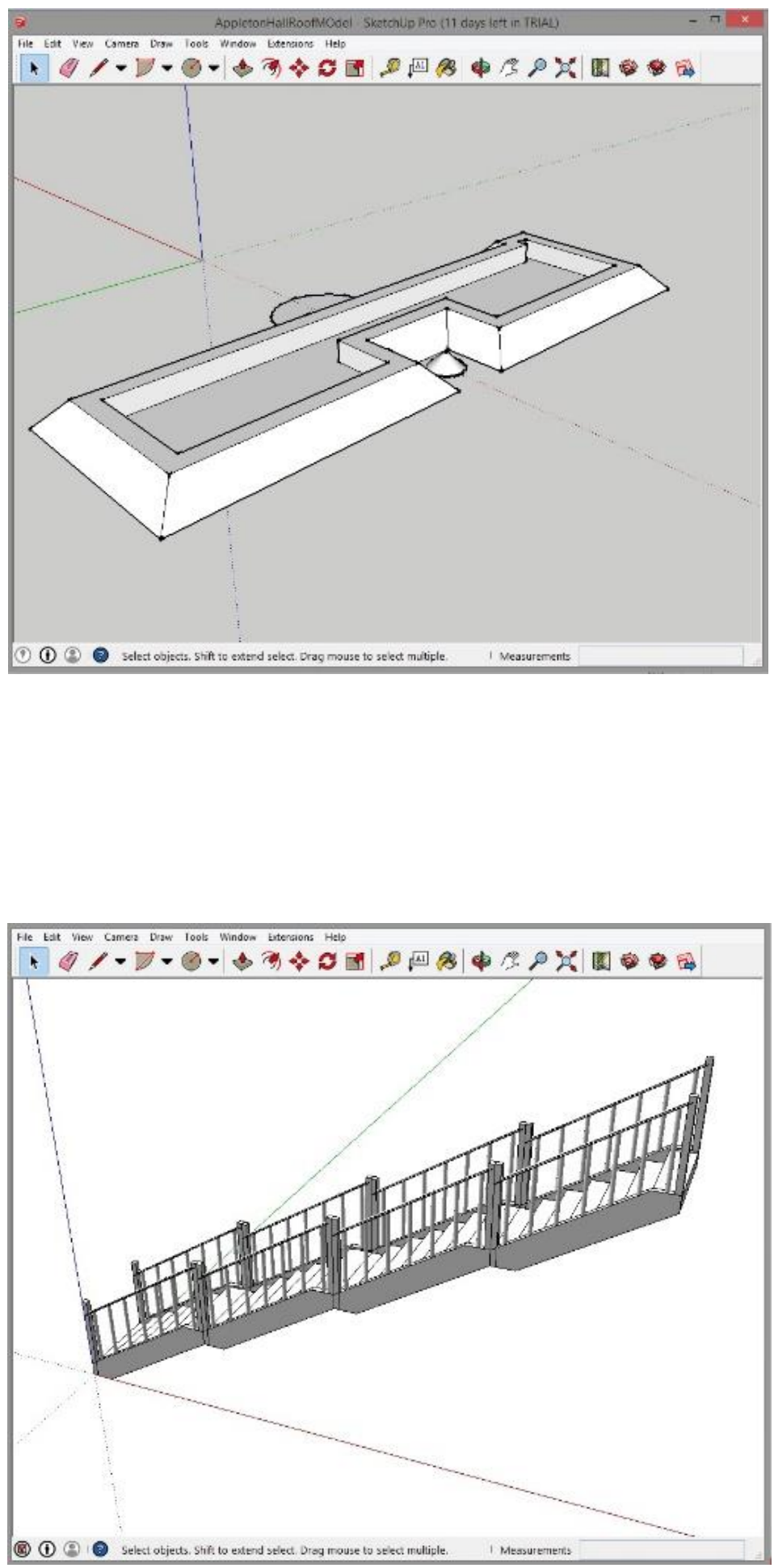

Figure 5-16: Editing roof and staircase details 


\subsubsection{Publishing the Scene}

This process was completed in order to share the result to a larger audience. The 3D model from CityEngine was published as a web scene that can be accessed and visualized from a web browser. The scene was published in .3WS format which is web-optimized to allow scenes to be viewed by a user within ArcGIS online and/or CloudCities platform. The client provided an enterprise account in their cloud space to host the project scene and share it with the public. The enterprise account allows members to upload more than $500 \mathrm{Mb}$, as well as configure the dashboard to visualize interactive scenarios and perform analysis. Figure 5-17 illustrates the web scene with a configured dashboard.

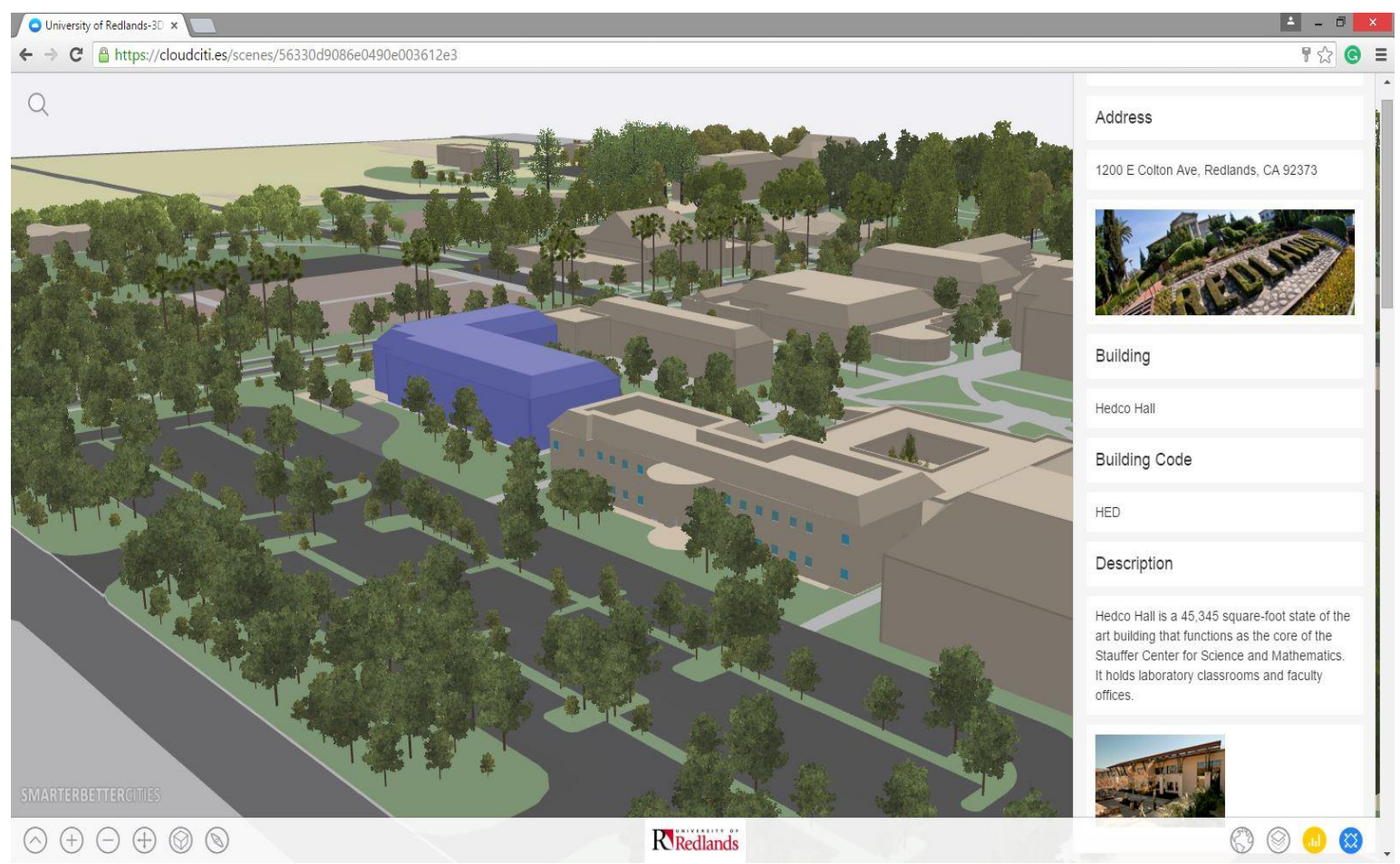

Figure 5-17: The 3D web scene hosted in CloudCities.

\subsection{Summary}

Chapter 5 discussed the implementation methods including: data creation, 3D indoor routing, and 3D modeling, and described the project products which were 3D network analysis and the 3D model. The analysis was done in ArcGIS for Desktop and the 3D model was completed by CityEngine and published as a scene hosted in CloudCities. 



\section{Chapter 6 - Results and Analysis}

This chapter covers the results of the project. The project was conducted as a proof of concept for $3 \mathrm{D}$ indoor routing to help users visualize $3 \mathrm{D}$ routes based on their user defined scenarios. The solution provided the user the ability to identify a route for handicapped people via the elevators, while the non-handicapped can use either the elevator or staircase. The project had two major outputs: 3D indoor routing and 3D web scene. The first is meant for the client, while the latter is meant for a public audience. Section 6.1 illustrates the two route scenarios which were Handicapped and Elevator use, and Non-Handicapped and Stairs use. Section 6.2 addresses the interactive 3D web scene and focuses on how the web scene may be used. This chapter ends with a summary in Section 6.3.

\subsection{D Indoor Routing Analysis}

The project focused on Appleton Hall for the indoor routing while the outdoor routing included East Hall, Lewis Hall, Hedco Hall, and Williams Hall. The 3D indoor routing analysis is divided into two scenarios: Handicapped and Elevator use, and NonHandicapped and Stairs use. All the required data were assembled in an ArcScene file (SXD). The SXD in the ArcScene application includes all the necessary layers to enable users to run the GP tool. The SXD file is included in the same folder containing the file geodatabase that contains the network dataset and the GP tool. To run the tool, a user needs to open the SXD and open the ArcCatalog window, then browse to the project file geodatabase and browse for a toolbox named Network. Within the Network toolbox is the 3D Indoor Routing GP tool. A user should double click the tool to open it. Figure 6-1 shows the tool interface 


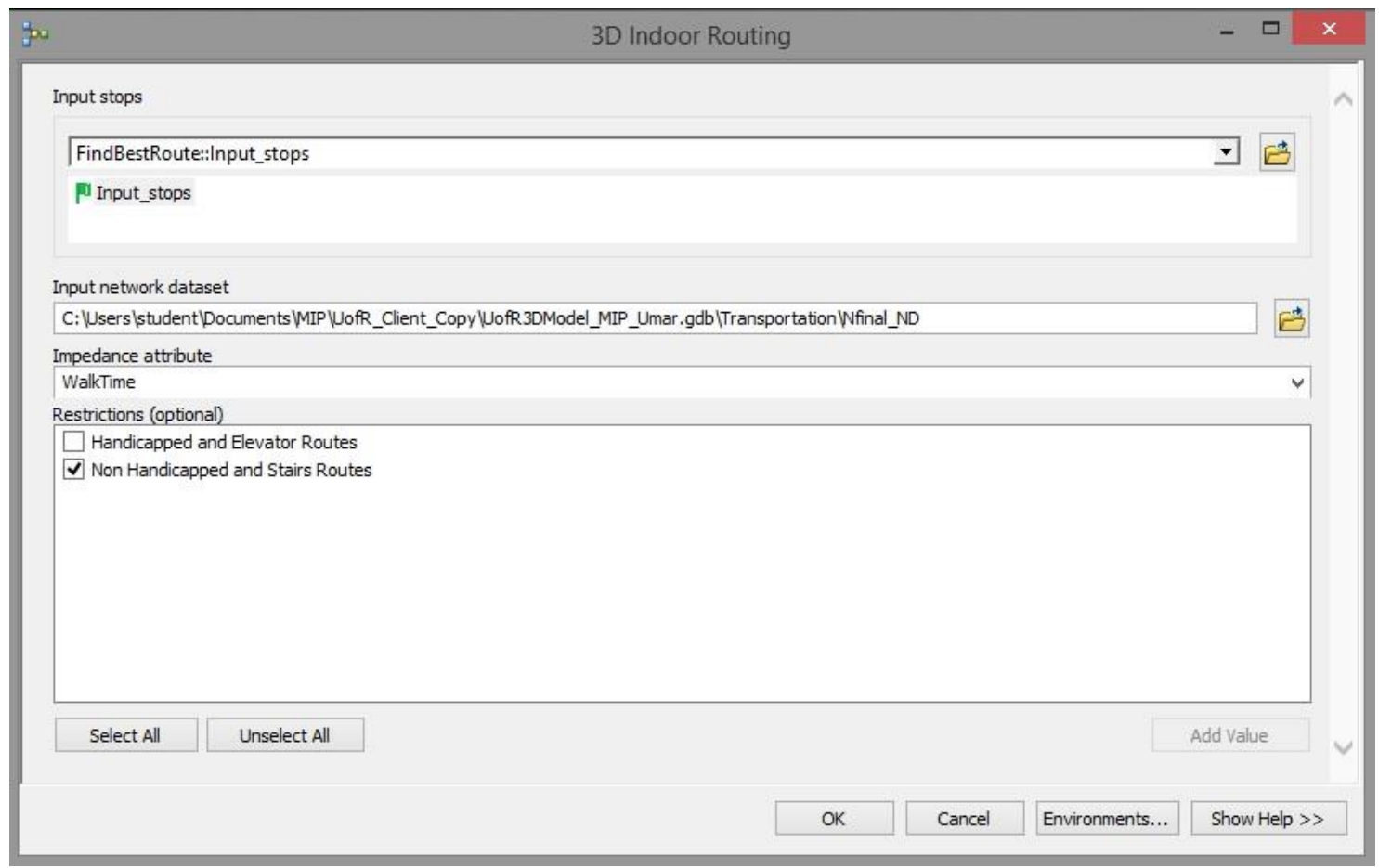

Figure 6-1: The 3D Indoor Routing Geoprocessing tool Interface.

The GP tool requires four user inputs to run the analysis: Input Stops, Input Network Dataset, Impedance Attribute, and Restrictions. These inputs are entered in the tool interface. The Input Stops provide two options: FindBestRoute:Input_Stops and Points. The FindBestRoute:Input_Stops option allows users to choose the desired stops (origin and destination) by clicking on the map. The Points option lets the users select stops from the Points feature class in the project database. The Input Network Dataset parameter lets the users choose the network dataset. This project has only one network dataset and therefore the user will leave the selected default network dataset. The Impedance attribute provides two methods of calculating routes. These were either by walk time as default or by length. The Restrictions provide an option where the user can choose the suitable restriction depending on whether they are handicapped or not or whether they need to use the elevator or the staircase. Figure 6-2 illustrates the first scenario which involves the handicapped and elevator use case 


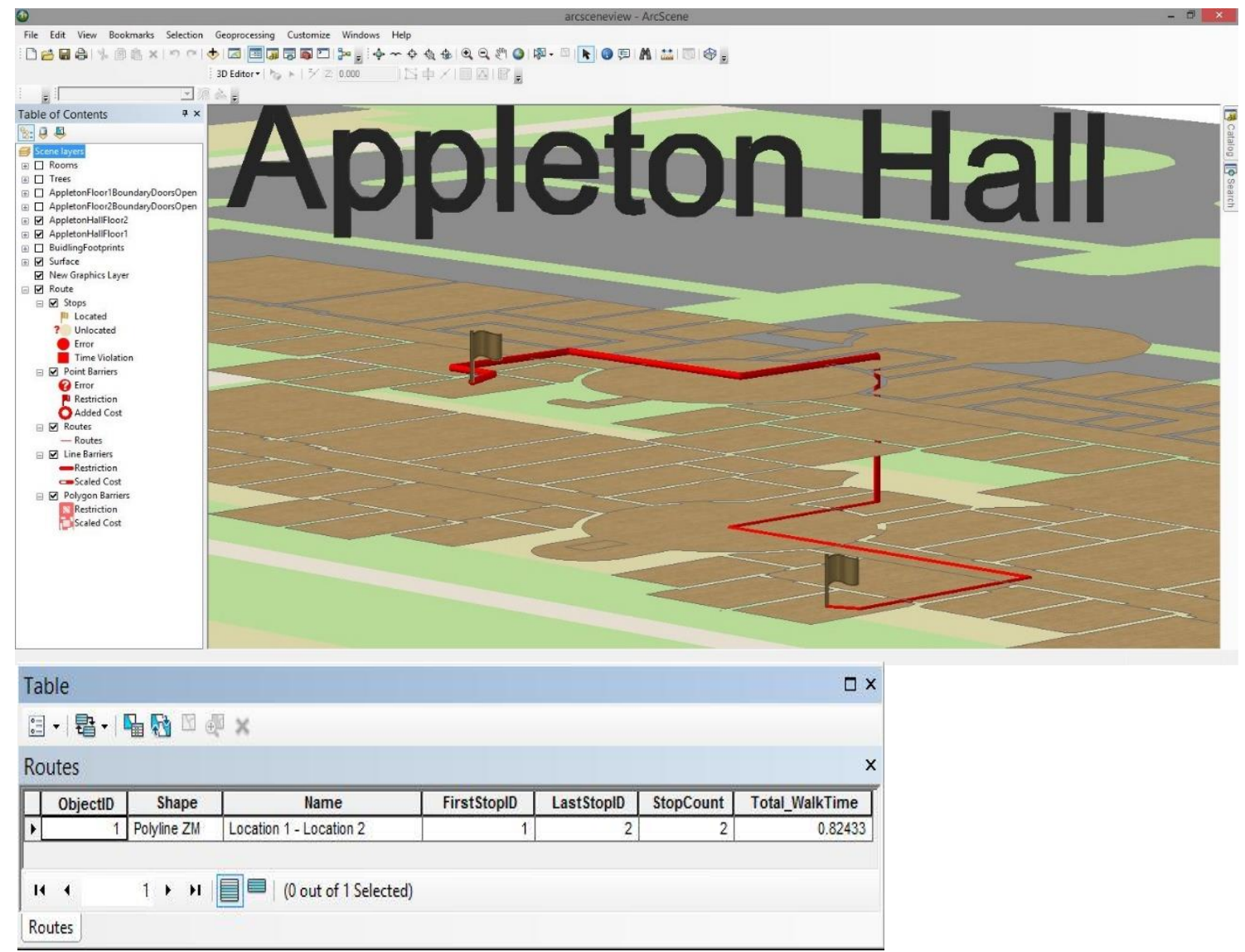

Figure 6-2: The Non-Handicapped and Stairs restricted uses scenario.

The attribute table of the route result shows the number of selected points, as well as the estimated time in minutes.

Figure 6-3 illustrates the second scenario for the optimal result of supporting the Non-Handicapped and Staircase use. 


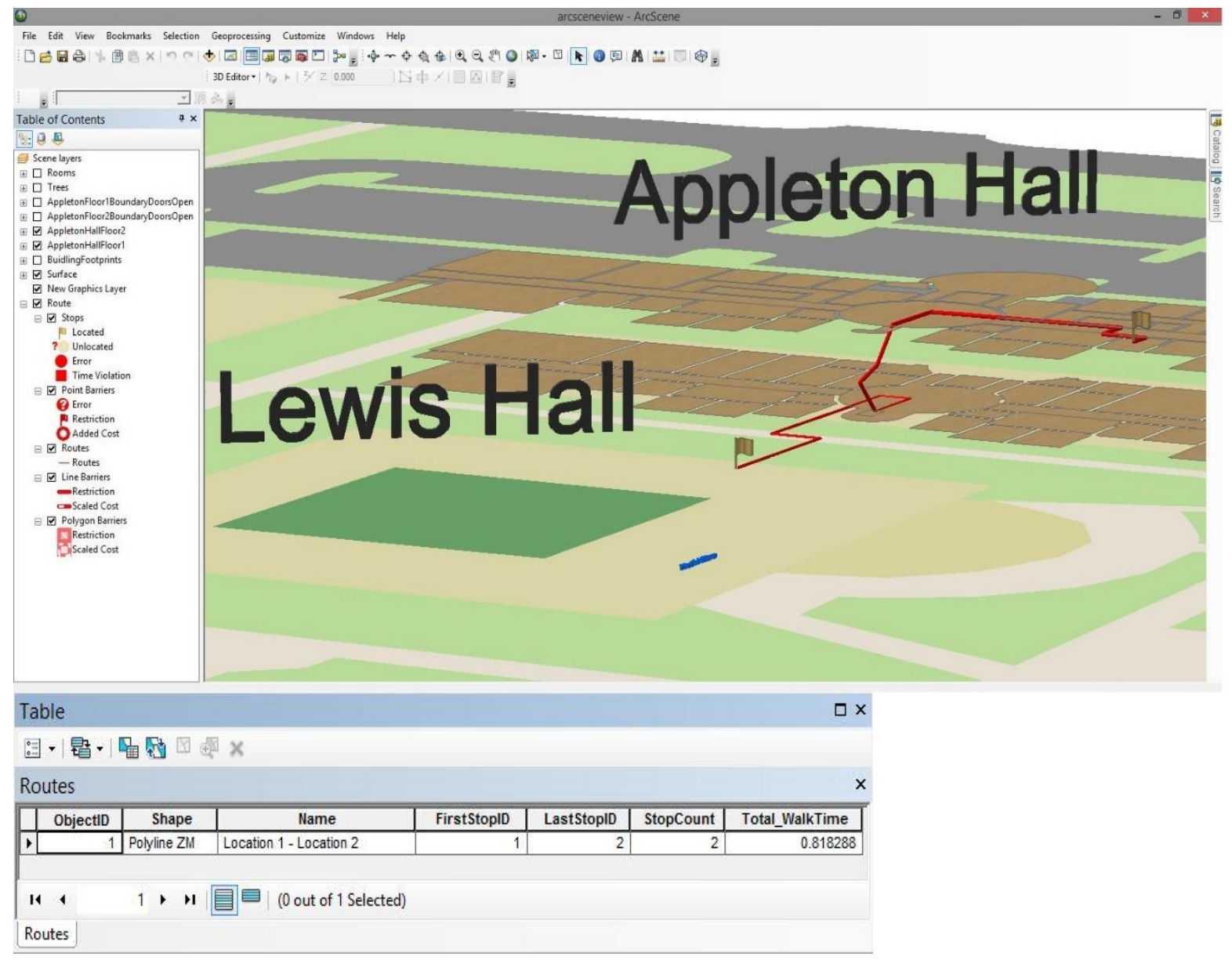

Figure 6-3: Route between indoor and outdoor networks using stairs scenario.

The scenario shown in Figure 6-3 illustrates a route result between two points where the first point is a room inside Appleton Hall and the second point is the entrance of Lewis Hall. The route attribute table illustrates the estimated walk time in minutes.

\subsection{D Web Scene}

Two versions of web scenes were published: one with all the contents and the second with only the basic layers (Panorama, Building footprints, Basemap, Trees, Base, Appleton Hall roof, Appleton Hall Floor1 Rooms, Appleton Hall Floor2 Rooms, First Floor Doors Windows, Second Floor Doors Windows, Staircases, Elevator, Route Scenarios). This was done to allow users to access and use the scene on their smartphones and tablets. Both scenes were hosted in the client web environment, CloudCities, which has the capability to customize the project dashboard. It supports illustration of the routes scenarios. The CloudCities used the HTML5 and WebGL to enable users to access the web scene via smartphones and tablets. Figure 6-4 shows the first web scene interface for representing different route scenarios. 


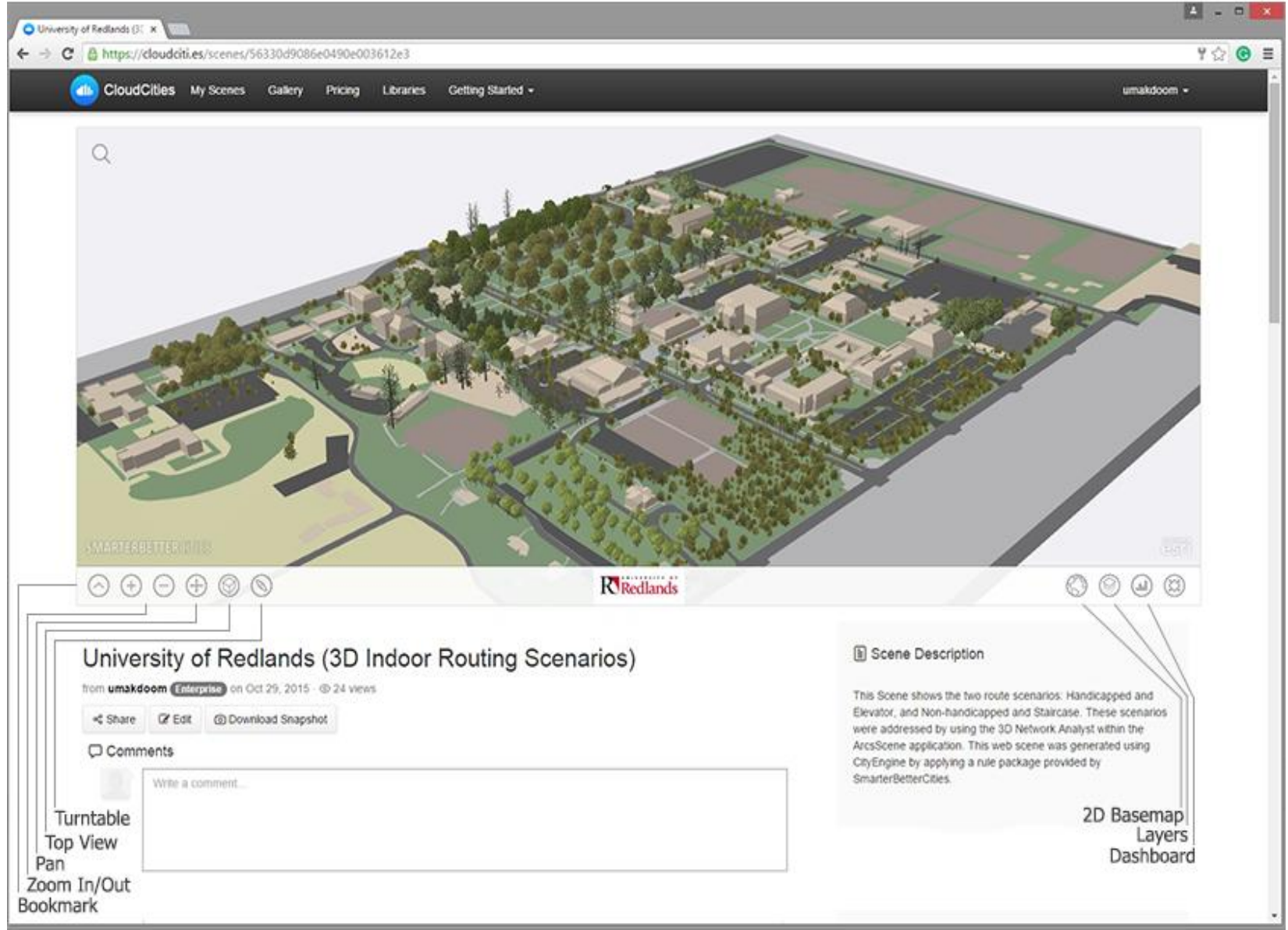

Figure 6-4: The 3D web scene for the University of Redlands.

The second web scene was published without including the route scenario layers to reduce the scene file. This web scene had to be less than $10 \mathrm{Mb}$ to be viewable on smartphones and tablets. Figure 6-5 illustrates the view of the web scene by using a smartphone. 


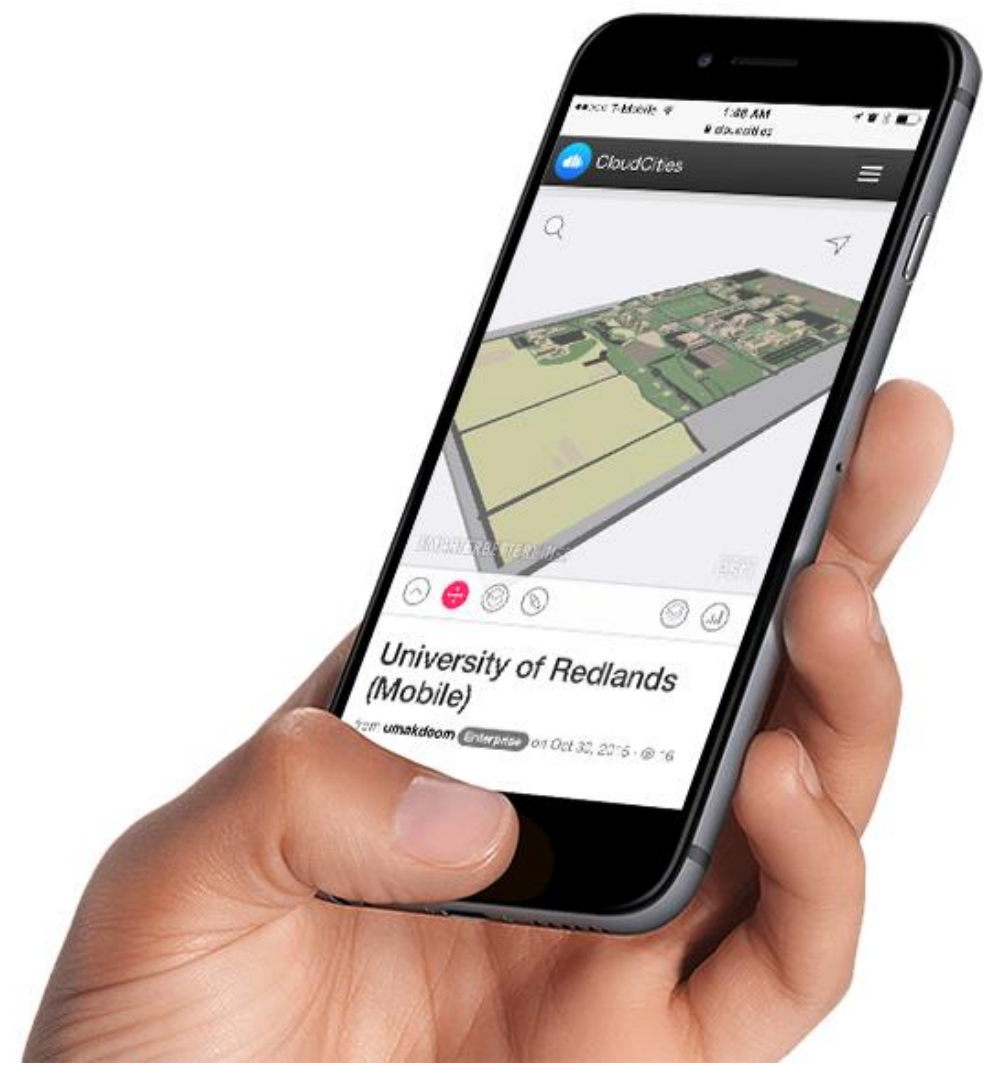

Figure 6-5: The 3D web scene on a smart phone.

The web scene dashboard contains: search capability, toggle layers, pop-upwindow, capture screenshots, 2D basemap viewer, share the scene, comments bar, Pan, Top view, Turntable, and selected bookmarks.

The search capability allows users to search for a specific building. The toggle layers allow the user to turn layers on and off so that they can view the scene with only the desired layers. The pop-up window provides information for the selected building, such as the university website link, building name, building code, building description, and building picture. Users can capture screenshots from the scene and download them as an image in .jpg format. The web scene was integrated with a 2D basemap view so that users can display both the web scene and interactive maps in $2 \mathrm{D}$ views. To share the scene in social media, the web scene provides a click button to share the scene link on common social media sites such as Facebook, Twitter, and LinkedIn. Not only limited to these media sites, it gives the option to copy and paste the link or embed it in other websites. Users can write comments and give their feedback on the scene through a comments bar below the scene. The pan button allows users to hold a 3D view of the web scene and move it as 2D view. The top view button helps users to view the web scene in $2 \mathrm{D}$ view. The turntable allows users to visualize the scene live movement in 360 degree. The bookmark includes different cameras the user can select to view the scene from different perspectives. 


\subsection{Summary}

This chapter explained the project results: the route scenarios, and the 3D web scene. The first result was focused on identifying the two route scenarios: Handicapped and Elevator use, and Non-Handicapped and Stair use. Both scenarios can be used to perform $3 \mathrm{D}$ routing analysis within and outside complex buildings, including the interior details. The second result, 3D web scene, may be used in the University online website to help visitors search for specific buildings. This project was a proof of concept to benefit both client and audiences by illustrating the capability of the $3 \mathrm{D}$ indoor routing. 



\section{Chapter 7 - Conclusions and Future Work}

The purpose of this project was to develop a 3D indoor routing solution as illustration for the model using the University of Redlands as the study area. The project was implemented by using GIS technologies to enable users to define Points Of Interest (POI) and generate a 3D route among the POIs. The product was also published as a web scene with sample results to allow users to visualize the 3D route from a web browser. The chapter is divided into two sections. Section 7.1 covers the project conclusion which elaborates on the project results: 3D indoor routing, and 3D model. Section 7.2 discusses possible future work.

\subsection{Conclusion}

The project data were hosted in a file geodatabase, which contained all the feature datasets, feature classes, topology, DTM, and orthophoto used in the project. The first result was a 3D indoor routing scenario. Within ArcGIS Network Analyst Extension, the 3D Network Analyst GP tool was used to build the 3D indoor routing scenarios: handicapped using elevator, and non-handicapped using staircase. These scenarios used different restrictions in the form of attributes in order to avoid either using staircase or elevator, depending on whether the user needs handicapped access.

The second result was the development of a 3D model and its publication as a web scene. The 3D model was implemented within the CityEngine environment (version 2014.1) by using rule packages, which were written using the Computer Generated Architecture (CGA) programming language. The final scene was published as .3WS file format and hosted in CloudCities. This enabled users to access it from their web browsers on desktops or smartphones and tablets. The client's web viewer, CloudCities, has the ability to customize dashboards to increase visualizing model scenarios. The dashboard was customized to give it a look and feel similar to the University of Redlands website. From the dashboard, users can search for buildings, capture screenshots, view a 2D basemap, detailed pop up window, comment on the product, and share the results on social media.

\subsection{Future Work}

The project generated data which were up to date as of the project completion. These data can be used for future work using: 3D Network Analyst, 3D Analyst, and design complex 3D models. The two results of this project were a proof of concept for the client. These workflows and sample results could be used to guide the development of a production level web application that enables 3D indoor routing across campus. It will be very helpful for the University of Redlands to implement a 3D model of this kind to the entire campus. By doing this, users and visitors to the university would be able to access various destinations on campus as quickly as possible. It would be helpful if this model was developed as a 3D web application capable of real time navigation on smart phones and tablets. The University could use this model to implement a 3D indoor evacuation plan for all of the university's buildings and facilities. 
Another opportunity to be considered for the advancement of this project is the data for the project. This project relied on data that required enhancement before they could provide the necessary details. In the future, the University of Redlands could invest in the data collection of data across the campus with specific data requirements and applications. These data requirements could be defined based on the anticipated 3D project outcomes so that the data are collected with specific details such as the heights of buildings, the presence of alarm systems, and alternate means of egress. 


\section{Works Cited}

Esri. (2015, May 2). ArcGIS for Network Analyst. Retrieved from Esri: http://www.esri.com/software/arcgis/extensions/networkanalyst

Goetz, M. (2012). Using Crowdsourced Indoor Geodata for the Creation of a ThreeDimensional Indoor Routing Web Application - See more at: http://www.mdpi.com/1999-5903/4/2/575/htm\#sthash.m2GoQLBQ.dpuf. Retrieved May 4, 2015

Han, L., Zhang, T., \& Wang, Z. (2014, May). The Design and Development of Indoor 3D Routing System. Journal of Software, 1223. Retrieved from http://ojs.academypublisher.com/index.php/jsw/article/view/jsw090512231228/92 93

Johnson, H. R. (2008). Montclair High School: A Multi-dimensional GIS Approach to Tactical Emergency Response. (Master's Thesis, University of Redlands). Retrieved May 6, 2015, from http://inspire.redlands.edu/gis_gradproj/58/

O’Connor, D. L. (2013). Solid Waste Collection Vehicle Route Optimization for City of Redlands, California. (Master's thesis, University of Redlands). Retrieved May 8, 2015, from http://inspire.redlands.edu/gis_gradproj/201

$\mathrm{Xu}$, M. (2014). Indoor Graph generation through Customizing TIN. (Master's Thesis, University of Redlands). Retrieved May 12, 2015 



\section{Appendix A. 3D Indoor Routing Web Scenes}

Two web scenes were published and hosted in CloudCities for University of Redlands.

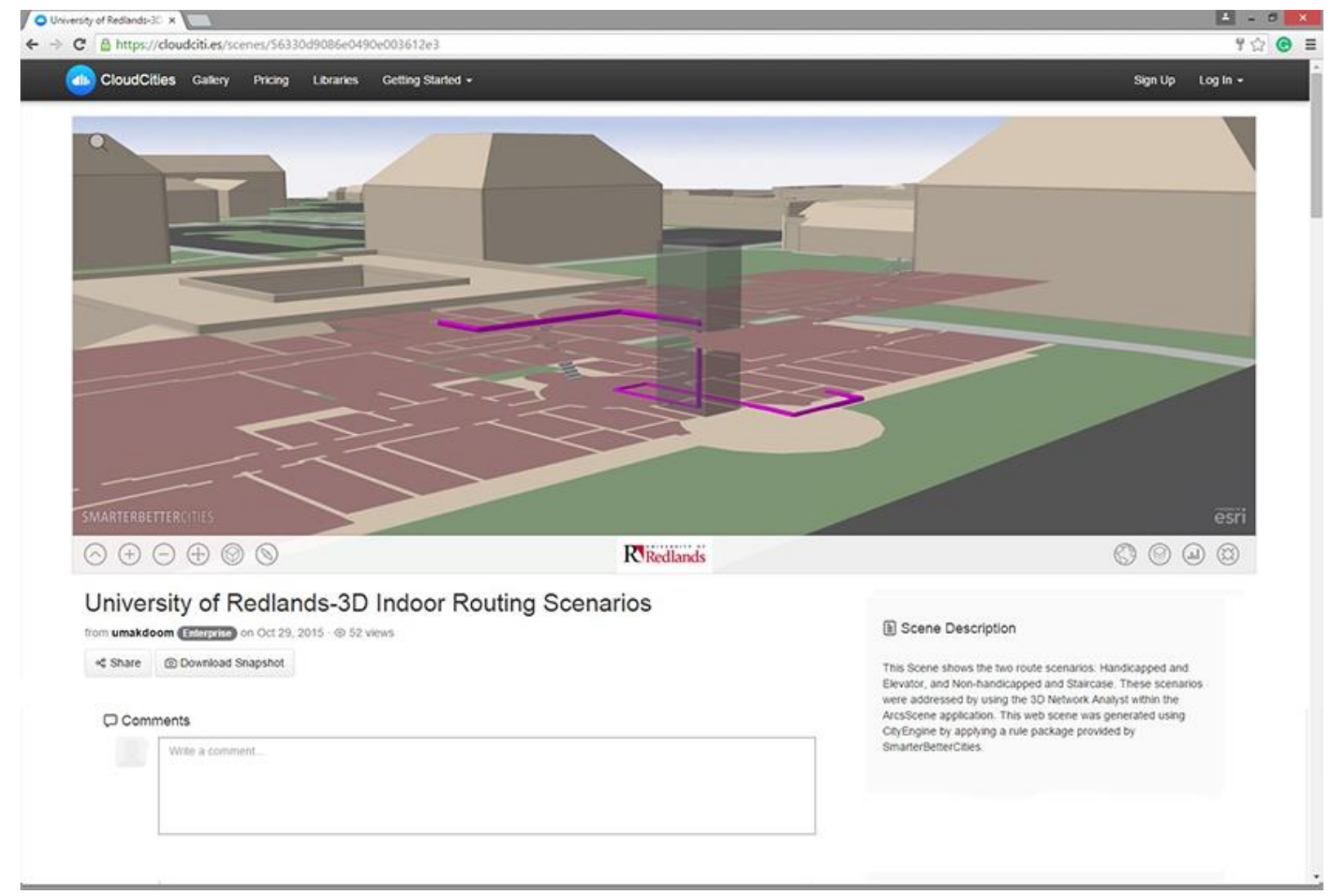

Web scene 1: 3D sample route of Handicap and Elevator use. 
O Unversy af Rosandis $x$

$\leftarrow$ C Q https:/cloudciti.es/scenes/56330d9086e0490e003612e]

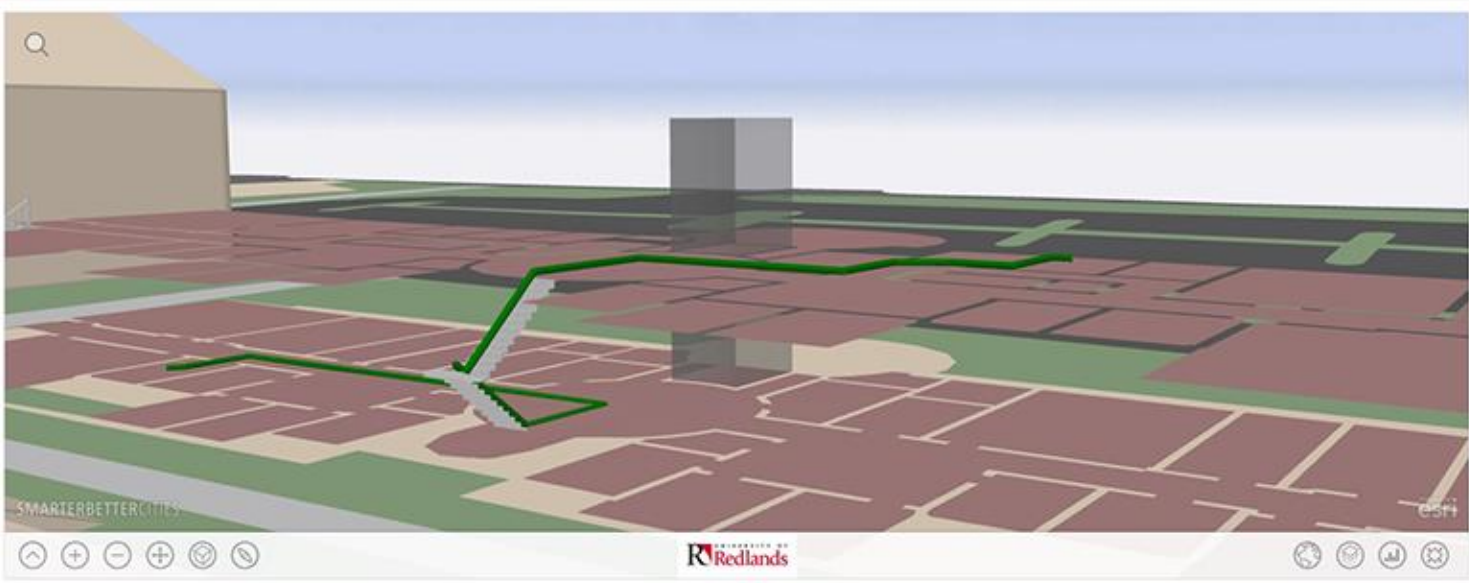

University of Redlands-3D Indoor Routing Scenarios

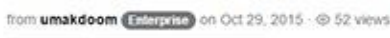

(1) Scene Description

< share QDonnibad Snapshot

This Scene shous the tho rove scenares. Hanscapped and

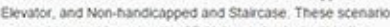

๑ comments

wete addressed by using the 30 Network Anatsst wethin the

Aarsingne by appling a rule package prowsecd by smanerbeserceses.

Web scene 2: 3D sample route of Non-Handicapped and stairs use.

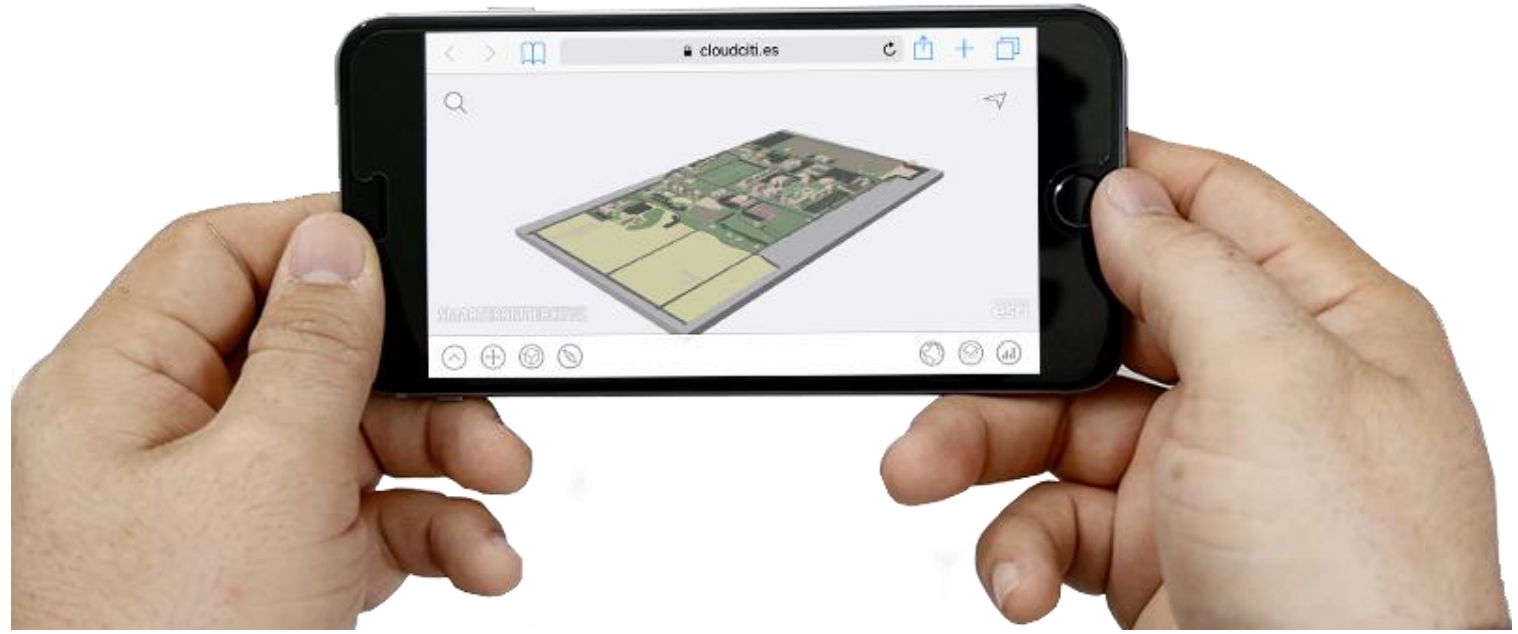

Web scene 3: 3D campus for University of Redlands-Mobile 


\section{Appendix B. Sample Code in CGA}

This is a sample code used to implement the 3D models and specify roof types. Downloaded from CGA rule package help in CityEngine.

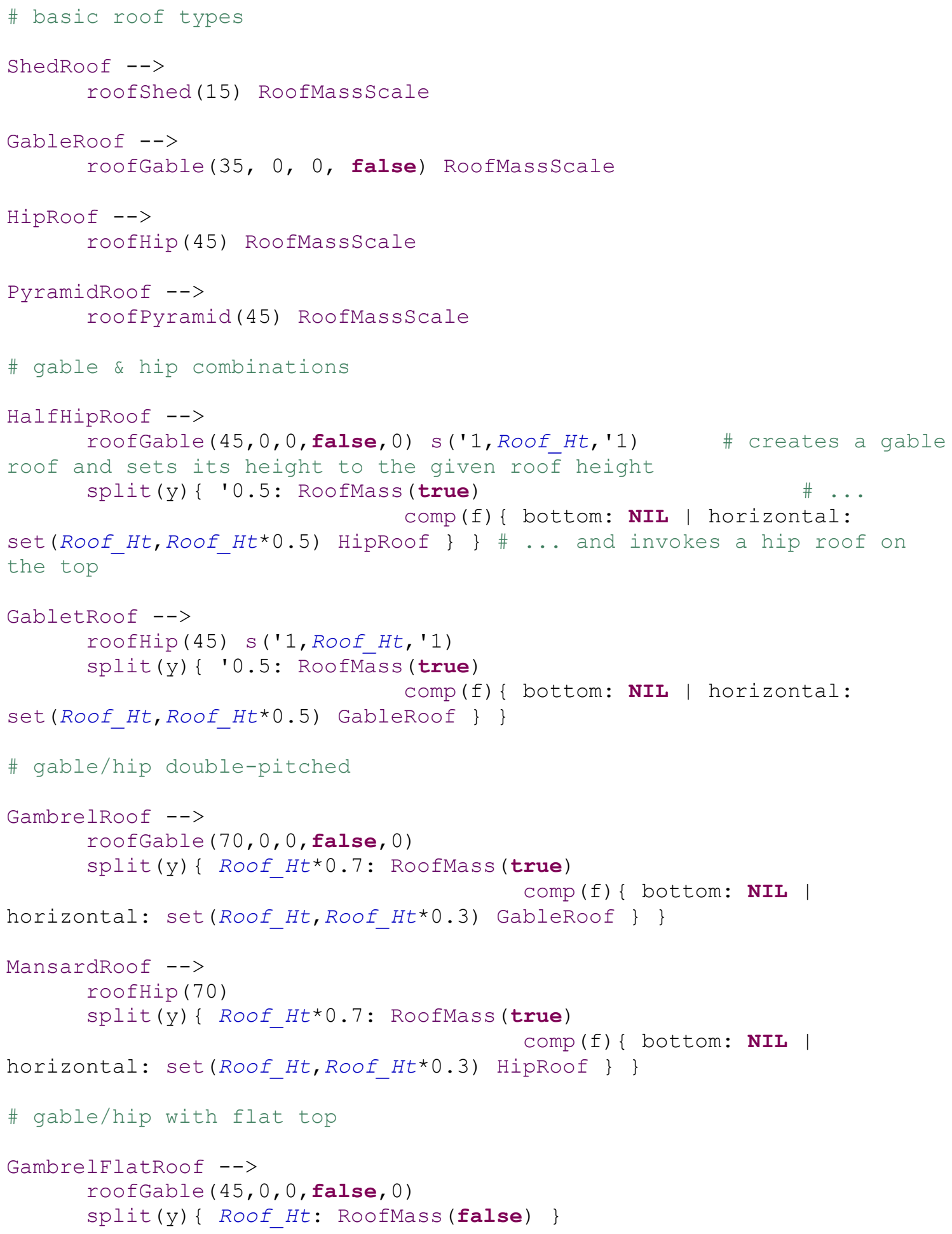




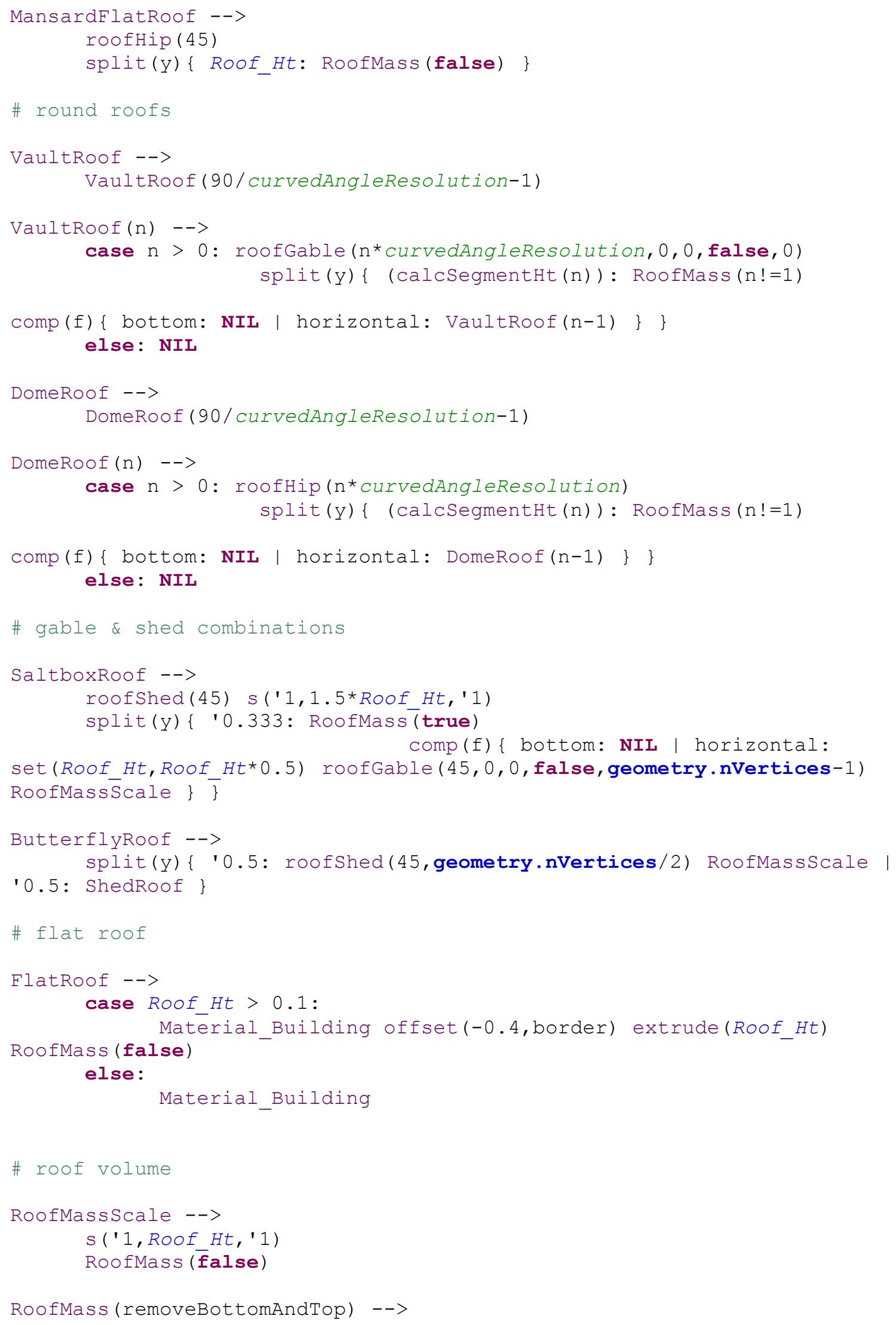


case removeBottomAndTop:

comp(f)\{ horizontal: Colorer | vertical: Material Building

| all: Material_Building \}

else: \# remove only the bottom face

comp(f)\{ bottom: Colorer | vertical: Material_Building |

all: Material_Building \}

Colorer-->

color ("\#ff0000") 

